\title{
Mining proteomic data to expose protein modifications in Methanosarcina mazei strain Gö1
}

\author{
Deborah R. Leon ${ }^{1+}$, A. Jimmy Ytterberg ${ }^{1+}$, Pinmanee Boontheung ${ }^{1+}$, Unmi Kim ${ }^{2+}$, Joseph A. Loo ${ }^{1,3,4}$, \\ Robert P. Gunsalus ${ }^{2,4 *}$ and Rachel R. Ogorzalek Loo ${ }^{3,4 *}$ \\ ${ }^{1}$ Department of Chemistry and Biochemistry, University of California, Los Angeles, Los Angeles, CA, USA \\ ${ }^{2}$ Microbiology, Immunology, and Molecular Genetics, University of California, Los Angeles, Los Angeles, CA, USA \\ ${ }^{3}$ Department of Biological Chemistry, David Geffen School of Medicine, University of California, Los Angeles, Los Angeles, CA, USA \\ ${ }^{4}$ UCLA-DOE Institute for Genomics and Proteomics, University of California, Los Angeles, Los Angeles, CA, USA
}

\section{Edited by:}

Sonja-Verena Albers, University of

Freiburg, Germany

Reviewed by:

Marco Moracci, National Research

Council of Italy, Italy

Benjamin Harry Meyer, University of

Freiburg, Germany

*Correspondence:

Robert P. Gunsalus, Microbiology, Immunology, and Molecular

Genetics, University of California,

Los Angeles, 1602 Molecular

Science BIdg., Los Angeles, CA

90095, USA

e-mail: robg@microbio.ucla.edu;

Rachel R. Ogorzalek Loo, Molecular

Biology Institute, University of

California, 406 Boyer Hall, Los

Angeles, Los Angeles, CA 90095,

USA

e-mail: rloo@mednet.ucla.edu

${ }^{\dagger}$ Present address:

Deborah R. Leon, Mass

Spectrometry Resource, Boston

University School of Medicine,

Boston, USA;

A. Jimmy Ytterberg, Department of

Medical Biochemistry and

Biophysics, Karolinska Institute,

Stockholm, Sweden;

Pinmanee Boontheung, Halliburton,

Houston, USA;

Unmi Kim, BP Biofuels, San Diego,

USA
Proteomic tools identify constituents of complex mixtures, often delivering long lists of identified proteins. The high-throughput methods excel at matching tandem mass spectrometry data to spectra predicted from sequence databases. Unassigned mass spectra are ignored, but could, in principle, provide valuable information on unanticipated modifications and improve protein annotations while consuming limited quantities of material. Strategies to "mine" information from these discards are presented, along with discussion of features that, when present, provide strong support for modifications. In this study we mined LC-MS/MS datasets of proteolytically-digested concanavalin A pull down fractions from Methanosarcina mazei Gö1 cell lysates. Analyses identified 154 proteins. Many of the observed proteins displayed post-translationally modified forms, including $O$-formylated and methyl-esterified segments that appear biologically relevant (i.e., not artifacts of sample handling). Interesting cleavages and modifications (e.g., $S$-cyanylation and trimethylation) were observed near catalytic sites of methanogenesis enzymes. Of 31 Methanosarcina protein $\mathrm{N}$-termini recovered by concanavalin A binding or from a previous study, only M. mazei S-layer protein MM1976 and its M. acetivorans C2A orthologue, MA0829, underwent signal peptide excision. Experimental results contrast with predictions from algorithms SignalP 3.0 and Exprot, which were found to over-predict the presence of signal peptides. Proteins MM0002, MM0716, MM1364, and MM1976 were found to be glycosylated, and employing chromatography tailored specifically for glycopeptides will likely reveal more. This study supplements limited, existing experimental datasets of mature archaeal $N$-termini, including presence or absence of signal peptides, translation initiation sites, and other processing. Methanosarcina surface and membrane proteins are richly modified.

Keywords: $S$-layers, archaeal surface proteins, Methanosarcina mazei, prokaryotic glycosylation, membrane proteins, concanavalin A

\section{INTRODUCTION}

Knowledge about Archaea and their proteins is limited, making their characterization important. Fortunately, tools are available to identify proteins at high throughput, while bioinformatic analyses can overlay existing knowledge onto this kingdom. Nevertheless, protein modifications unique to these organisms and/or rare in well-studied microbes may elude us, primarily because high throughput proteomic methods focus on matching peptide fragment data to what can be anticipated, primarily from the genome sequence.

Progress in understanding archaeal cell surface structures has been hindered by the limited availability of experimental results, and any new protein modifications that are revealed may hint at function. Here peptide tandem mass spectrometry (MS/MS) datasets from previous investigations of Methanosarina S-layer and surface-exposed proteins (Francoleon et al., 2009; Rohlin et al., 2012), as well as from mixtures recovered by concanavalin A binding were selected for further analysis, motivated by interest in how protein modifications can impact organisms' interactions with their environment and with other organisms.

The above-mentioned emphasis on matching high throughput proteomic data to predictions means that unassigned mass spectra, (often 90\% of all data) are ignored (Savitski et al., 2005; Baumgartner et al., 2008; Falkner et al., 2008; Menschaert et al., 
2009; Hahne et al., 2013). In principle, unassigned proteomic data could be a treasure trove. In practice, its value depends on sample complexity (whether it contains $\sim 5000$ or 50,000 tryptic peptides), the protein and/or peptide separation strategies employed for its acquisition [single-dimension liquid chromatography (LC) of tryptic peptides vs. two-dimensional polyacrylamide gel electrophoresis (2D-PAGE) of proteins followed by peptide LC], and on the quality of the tandem mass spectrometry (MS/MS) data.

There are many reasons why peptide tandem mass spectra may be unassigned in these complex experiments:

1. The spectra may be poor in quality and/or low in information content.

2. The MS/MS spectra may be derived from a mixture, rather than from a single peptide.

3. The spectra may be derived from a peptide that is modified in a manner not considered by the algorithm.

High throughput workflows compromise between speed and depth of analysis, with "success" generally assessed by the number of proteins identified at a specified peptide or protein false discovery rate (FDR). This gene-centric approach does not differentiate between modified and/or processed forms of proteins. Typically, only modifications related to sample handling are considered (Schmidt et al., 2005) to balance sensitivity (number of peptides or proteins identified) with specificity (low false discovery rate). If post-translational modifications (PTMs) are pursued in high-throughput environments, modified peptides are typically enriched via PTM-specific immunoprecipitation or other affinity capture methods; e.g., phosphopeptide binding to $\mathrm{TiO}_{2}$.

Skillful data mining can recover valuable information about unanticipated modifications from high throughput proteomic data. Some strategies include:

1. Performing an error-tolerant search (Creasy and Cottrell, 2002); i.e., a second search limited to proteins detected in the initial search. It attempts to match mass spectra by considering one additional modification-type from the UniMod collection or single amino acid substitutions (Creasy and Cottrell, 2004). It also relaxes enzyme specificity, e.g., only the $N$ - or $C$-terminus of a peptide must conform to trypsin's known cleavage specificity, rather than both.

2. Searching against the genome sequence translated in 6-reading frames (three forward and three reverse strand translations). This approach overcomes DNA sequencing errors, missed open reading frames, incorrect start or stop sites, and alternate initiation. It can also be employed in an error-tolerant mode to overcome nucleobase substitutions.

3. Attempting to match spectra by assuming that one residue's mass has been shifted by some amount (within a specified range) or by clustering related spectra (Savitski et al., 2006; Bandeira et al., 2007; Falkner et al., 2008; Wilhelm and Jones, 2014).

4. Manual or computer-assisted de novo interpretation of mass spectra.
Evaluating accuracy is challenging for any data mining strategy. When searches are limited to relatively common modifications, it may be possible to calculate separate false discovery rates for the modified peptides. But when almost anything is possible, confirmatory information must be sought elsewhere.

Here, we illustrate how proteomic datasets can be mined to recover information about Methanosarcina mazei protein modifications and describe some characteristic mass signatures that assist in validating that modifications are present. Clearly, methods including antibody blotting, functional group specific staining, and chemical derivatization also provide essential verification. The focus of this manuscript is on mining existing data to recover information about unanticipated modifications. The knowledge may suggest protein forms (proteoforms) to track in future studies, follow-up experiments to confirm the modifications, it may hint at protein function, or it may simply improve protein annotations.

\section{MATERIALS AND METHODS CELL CULTIVATION}

M. mazei Gö1 was grown at $37^{\circ} \mathrm{C}$ as single cells (non-aggregated) in $p H 6.8$ basal mineral medium prepared by the Hungate technique and supplemented with $0.05 \mathrm{M}$ methanol as the sole source of carbon and energy (Sowers et al., 1993). Medium osmolarity was defined by $0.2 \mathrm{M} \mathrm{NaCl}$. Cultivation employed $10-\mathrm{mL}$ anaerobic tubes (Difco, Sparks, MD) sealed with a $\mathrm{N}_{2}-\mathrm{CO}_{2}(4: 1)$ atmosphere. Cultures were harvested at an average $\mathrm{OD}_{600}$ of $\sim 1.5$.

\section{CRUDE EXTRACT/LYSATE PREPARATION}

Eight tubes of $10-\mathrm{mL}$ anaerobic cultures were unsealed and their contents were transferred to $15-\mathrm{mL}$ Falcon ${ }^{\mathrm{TM}}$ centrifuge tubes. Cells were sedimented at room temperature for $10 \mathrm{~min}$ in a swing bucket rotor at $1125 \times g$. After centrifugation, $500 \mu \mathrm{L}$ of chilled lysis buffer was added to each tube [2\% (w/v) CHAPS (3-(3cholamidopropyl) dimethylammonio-1-propanesulfonate) in $\mathrm{pH}$ 7.5, $50 \mathrm{mM}$ Tris, $0.15 \mathrm{M} \mathrm{NaCl}, 1 \mathrm{mM} \mathrm{CaCl}_{2}$, and $1 \mathrm{mM} \mathrm{MnCl}_{2}$ supplemented with $2.25 \mu \mathrm{L}$ Sigma P8465 protease inhibitor]. The cell pellets were disrupted further by multiple freeze/thaw cycles interspersed with vortexing. The lysates were transferred to $1.5 \mathrm{~mL}$ microcentrifuge tubes for centrifugation at $16,000 \times$ $g$ for $15 \mathrm{~min}$ at $4^{\circ} \mathrm{C}$. The soluble lysate was retained for analysis.

\section{CONCANAVALIN A GLYCOPROTEIN ENRICHMENT}

Our previous purification was modified slightly (Francoleon et al., 2009). Briefly, each of four 5-mL centrifuge columns (Pierce, Rockford, IL) was loaded with a $2 \mathrm{~mL}$ slurry of Con Acoupled agarose beads (Vector Laboratories, Burlingame, CA). The beads were washed with $3 \mathrm{~mL}$ of $50 \mathrm{mM}$ Tris, $0.15 \mathrm{M} \mathrm{NaCl}$ $(p H$ 7.5) seven times, followed by six equilibrating washes with $2 \mathrm{~mL}$ binding buffer [BB, $50 \mathrm{mM}$ Tris, $0.15 \mathrm{M} \mathrm{NaCl} 1 \mathrm{mM} \mathrm{CaCl}_{2}$, $1 \mathrm{mM} \mathrm{MnCl}_{2}$ ( $p H$ 7.5)]. After equilibration, $1 \mathrm{~mL}$ of lysate and $1 \mathrm{~mL}$ of BB buffer were added to each column for incubation in a room temperature rotor. After $30 \mathrm{~min}$, the column flow through was collected by centrifugation and discarded. The protein-bound beads were washed 10 times to minimize non-specific binding: (1) five washes, each with $2 \mathrm{~mL}$ of $\mathrm{BB}$ buffer supplemented 
with $0.1 \%$ Tween-20, followed by (2) five 2-mL washes with $50 \mathrm{mM}$ of $\left(\mathrm{NH}_{4}\right) \mathrm{HCO}_{3}(p H 7.8)$. Glycoproteins were eluted from the lectin media twice: (1) Con A beads were incubated in $2 \mathrm{~mL}$ of elution buffer [ $50 \mathrm{mM}\left(\mathrm{NH}_{4}\right) \mathrm{HCO}_{3} / 0.2 \mathrm{M}$ methyl- $\alpha-\mathrm{D}$ mannopyranoside/0.2 M methyl- $\alpha$-D-glucopyranoside $(p H$ 7.8)] for $10 \mathrm{~min}$ at room temperature, and centrifuged to recover the eluate. (2) The elution was repeated with $1 \mathrm{~mL}$ of buffer. The combined eluate was concentrated to $1.6 \mu \mathrm{g} / \mu \mathrm{L}$ (Pierce BCA assay) by ultrafiltration through an Amicon ${ }^{\circledR} 50 \mathrm{kDa}$ cut-off cellulose membrane (Millipore, Billerica, MA).

Multiple enrichments were also performed on a smaller scale in a manner similar to that described above, but without ultrafiltration.

\section{IN-SOLUTION TRYPSIN, GLU-C AND ASP-N PROTEOLYSIS}

Each proteolytic digestion used $50 \mu \mathrm{L}$ of concentrated Con A eluate ( $\sim 78 \mu \mathrm{g}$ of total protein) which, prior to digestion, was precipitated at $-20^{\circ} \mathrm{C}$ overnight in 9 volumes of chilled acetone. Protein precipitate was recovered by centrifugation at $4^{\circ} \mathrm{C}$, $16,000 \times g$ for $20 \mathrm{~min}$. Pellets were washed in $500 \mu \mathrm{L}$ of chilled $80 \%$ acetone $/ 10 \%$ methanol $/ 0.2 \%$ acetic acid.

For trypsin digestion, the protein was resuspended in $20 \mu \mathrm{L}$ of room temperature dimethyl sulfoxide (DMSO) with $600 \mathrm{rpm}$ shaking for $30 \mathrm{~min}$ (Ytterberg et al., 2006). The solution was diluted to $30 \% \mathrm{DMSO} / 50 \mathrm{mM}\left(\mathrm{NH}_{4}\right) \mathrm{HCO}_{3}$ and sequencing grade trypsin (Promega, Madison, WI) was added at a 1:20 enzyme:protein ratio $(w / w)$. Digestion proceeded overnight at $37^{\circ} \mathrm{C}$ with $300 \mathrm{rpm}$ shaking.

For Glu-C digestion, precipitated protein was resuspended in $131 \mu \mathrm{L}$ of $p H 7.8,25 \mathrm{mM}\left(\mathrm{NH}_{4}\right) \mathrm{HCO}_{3}$ and 1:20 $(w / w)$ GluC:protein (sequencing grade Staphylococcus aureus Protease V-8, Roche, Indianapolis, IN). The reaction proceeded for $4 \mathrm{~h}$ with $300 \mathrm{rpm}$ shaking in a $25^{\circ} \mathrm{C}$ incubator.

Asp-N cleavage employed sequencing grade Pseudomonas fragi Asp-N (Roche) at 1:20 Asp-N:protein $(w / w)$. The protein pellet, resuspended in $131 \mu \mathrm{L}$ of $p H 7.5,25 \mathrm{mM}$ Tris buffer, was incubated for $4 \mathrm{~h}$ at $37^{\circ} \mathrm{C}$ with $300 \mathrm{rpm}$ shaking.

\section{Nano-HPLC and data dependent MS/MS}

Aliquots $(\sim 5 \mu \mathrm{g})$ of trypsin- and Glu-C-digested peptides were dried by vacuum centrifugation and resuspended in $125 \mu \mathrm{L}$ of $5 \%$ formic acid (FA) to $\sim 40 \mathrm{ng} / \mu \mathrm{L}$. Asp-N digested proteins $(\sim 10 \mu \mathrm{g}$ ) were desalted using a C-18 spin column (Pierce), dried, and resuspended to $\sim 40 \mathrm{ng} / \mu \mathrm{L}$ in $5 \%$ formic acid.

Peptide mixtures were analyzed by liquid chromatographytandem mass spectrometry (LC-MS/MS) with ESI (electrospray ionization) on an Applied BioSystems QSTAR ${ }^{\circledR}$ Pulsar XL quadrupole time-of-flight mass spectrometer equipped with a nanoelectrospray interface (Protana), a Proxeon (Odense) nanobore stainless steel emitter ( $30 \mu \mathrm{m}$ ID), and an LC Packings nano-LC system as described previously (Francoleon et al., 2009). Homemade pre- $(150 \times 5 \mathrm{~mm})$ and analytical $(75 \mu \mathrm{m} \times$ $150 \mathrm{~mm}$ ) columns were packed with Jupiter Proteo C12 $4-\mu \mathrm{m}$ resin (Phenomenex). Typically $6 \mu \mathrm{L}$ of sample was loaded onto the precolumn, washed with $0.1 \%$ FA for $4 \mathrm{~min}$ and transferred to the LC column. The $200 \mathrm{~nL} / \mathrm{min}$ mobile phase gradient employed $3-6 \% \mathrm{~B}$ in $6 \mathrm{~s}, 6-24 \% \mathrm{~B}$ in $18 \mathrm{~min}, 24-36 \% \mathrm{~B}$ in $6 \mathrm{~min}, 36-80 \%$
$\mathrm{B}$ in $2 \mathrm{~min}$, and $80 \% \mathrm{~B}$ for $7.9 \mathrm{~min}$. The column was equilibrated with $3 \% \mathrm{~B}$ for $15 \mathrm{~min}$ prior to the next run. Eluents used were $0.1 \% \mathrm{FA}$ (aq) (solvent A) and $95 \% \mathrm{CH}_{3} \mathrm{CN}$ containing $0.1 \% \mathrm{FA}$ (solvent B).

Peptide product ion spectra were recorded automatically by IDA (information-dependent analysis) software on the mass spectrometer. Protein sequence searches employed a conservative mass tolerance of $0.3 \mathrm{Da}$ for both precursor and product ions, and 1 (trypsin) or 2 (Asp-N and Glu-C) missed cleavages. Proteins hits were accepted based on $\geq 2$ ascribed peptides, at least of one which possessed a MOWSE score $\geq 26$ $(p \leq 0.02)$ with MuDPIT scoring. Identifications based on single peptides are presented separately. Correspondences between MS/MS spectra and all ascribed sequences were also verified manually.

\section{Nano-HPLC and data independent acquisition MS/MS}

The peptide mixtures described above were also analyzed by LCESI-MS/MS on a Xevo ${ }^{\mathrm{TM}}$ quadrupole time-of-flight MS (Waters Corporation) equipped with a Universal NanoFlow Sprayer interface and pre-cut Pico Tip Emitter $(360 \mu \mathrm{m}$ OD $\times 20 \mu \mathrm{m}$ ID, $10 \mu \mathrm{m}$ tip; $2.5^{\prime \prime}$ long), connected on-line to a nanoACQUITY ${ }^{\circledR}$ UltraPerformance ${ }^{\circledR}$ HPLC system (Waters Corporation). The nanoACQUITY ${ }^{\circledR}$ system was equipped with Waters' $5 \mu \mathrm{m}$ Symmetry $\mathrm{C}_{18}, 180 \mu \mathrm{m} \times 20 \mathrm{~mm}$ reversed-phase trap and $1.7 \mu \mathrm{m}$ BEH130 $\mathrm{C}_{18}, 75 \mu \mathrm{m} \times 100 \mathrm{~mm}$ reversed-phase analytical columns. Both columns were maintained at $40^{\circ} \mathrm{C}$. Typically $3 \mu \mathrm{L}$ of samples were injected onto the precolumn in aqueous $1 \%$ $\mathrm{CH}_{3} \mathrm{CN} / 0.1 \% \mathrm{FA}$ at a flow rate of $5 \mu \mathrm{L} / \mathrm{min}$ for $3 \mathrm{~min}$. Mobile phase A was water with $0.1 \%$ FA $(v / v)$ and mobile phase B was $\mathrm{CH}_{3} \mathrm{CN}$ with $0.1 \% \mathrm{FA}$. After desalting and concentrating in the trap column, peptides were transferred to the analytical column and resolved by a gradient of 3-60\% mobile phase B delivered over $30 \mathrm{~min}$ at a flow rate of $300 \mathrm{~nL} / \mathrm{min}$, followed by a 15 min wash with $95 \% \mathrm{~B}$ and 15 min re-equilibration at the initial conditions (3\% B, 97\% A).

The $\mathrm{Xevo}^{\mathrm{TM}}$ quadrupole time-of-flight MS was operated in positive ion, V-mode with an average resolution of 9500 FWHM. Full scan mass spectra were acquired from 50 to $2000 \mathrm{~m} / z$. LC-MS and $\mathrm{LC}-\mathrm{MS}^{\mathrm{E}}$ data were collected in alternating low and high collision energy modes throughout the run (Silva et al., 2005), with each spectrum acquired for $1 \mathrm{~s}$ per mode.

Proteins were identified using the ProteinLynx Global SERVER $^{\mathrm{TM}}$ version 2.4 search engine (PLGS, Waters Corporation). All ions were lock mass corrected, de-isotoped, and decombulated (charge state reduced). PLGS software ascribed collision induced dissociation (CID) product ions to their precursor peptides by time-aligning low- and high-energy-detected ions with a retention time tolerance of approximately $\pm 0.05 \mathrm{~min}$. Sequence searches were restricted to fully tryptic products with up to one missed cleavage, variable methionine oxidation and $N$-terminal Gln/Glu conversion to pyro-Glu, and peptide and product ion tolerances of 10 and $25 \mathrm{ppm}$, respectively. Proteins hits were accepted based on $\geq 2$ ascribed peptides, each with 3 or more product ions, and at least seven fragment ions per protein. Correspondences between MS/MS spectra and ascribed sequences were also evaluated manually. 


\section{RESULTS AND DISCUSSION}

We identified 154 proteins from concanavalin A pull down fractions and cell surface labeling. The following sections describe these proteins and the additional information that can be recovered by data mining.

\section{IDENTIFICATIONL OF CONCANAVALIN A INTERACTING PROTEINS}

The archaeal cytoplasmic membrane has been described as fulfilling the role of the eukaryotic endoplasmic reticulum (YuristDoutsch et al., 2008) because archaeal glycosylation machinery is membrane-bound. Cell $N$-linked glycoproteins are expected to localize to the cytoplasmic membrane or the associated outer cell envelope region (Eichler, 2003; Albers et al., 2006; Messner, 2009). Thus, glycoprotein capture methods (e.g., lectin affinity chromatography) complement cell surface labeling (Francoleon et al., 2009) for enriching archaeal surface and membrane proteins.

To support ongoing studies characterizing protein glycosylation, M. mazei cell lysate proteins were lectin affinity-captured through direct and indirect binding using Con A, for which the subset of direct binders typically includes glycoproteins containing $\alpha$ - $D$-mannose and $\alpha$ - $D$-glucose (Kornfeld and Ferris, 1975; Baenziger and Fiete, 1979; Debray et al., 1981; Jaipuri et al., 2008). Here, we describe what can be learned from LC-MS/MS analyses of the Con A eluate with subsequent data mining. Further studies that employed additional dimensions of separation [e.g., hydrophilic interaction chromatography (HILIC) followed by reversed phase liquid chromatography], in concert with advanced ion activation techniques including infrared multiphoton dissociation (Zubarev, 2004; Cooper et al., 2005) will be discussed elsewhere (Leon et al., in preparation). Those methods greatly increase the numbers of glycoproteins observed, improve ability to localize glycosylation sites, and characterize individual glycan chains. Nevertheless, useful information can be gleaned from these initial LC-MS/MS experiments.

Not all proteins recovered from the Con A eluate are necessarily glycosylated. Indirect binding partners do not bind Con A directly, but associate with one or more direct (glycosylated) interactors; e.g., other subunits of a non-covalent complex. From M. mazei Gö1, 99 Con A eluate proteins were identified by LC-MS/MS with $\geq 2$ peptides (Table 1). An additional 55 protein identifications based on a single peptide are presented in Supplemental Table S-1.

Standard proteomic search strategies do not reveal unknown glycopeptides, because it is not possible to predict the amount by which peptide masses are incremented. However, manual MS/MS analysis of, e.g., HILIC fractions, reveals some precursor masses (peptides) that are obviously glycosylated, because they dissociate to release low mass-to-charge ratio $(\mathrm{m} / \mathrm{z})$ ions, known as oxonium ions, that are characteristic of different sugars (Mechref, 2012). Ions at 163.06 and $127.06 \mathrm{~m} / z$; e.g., signal that hexoses are present, while $204.09,186.09$, and $168.09 \mathrm{~m} / z$ reflect present $\mathrm{N}$-acetylhexosamines.

Bona fide glycosylated proteins, revealed by their oxonium ions in peptide MS/MS spectra, were identified from Con A eluate as MM0002, MM0716, MM1364, and S-layer protein MM1976. It is unlikely that these are the only glycoproteins within M. mazei.
Indeed, glycoprotein-specific staining (Francoleon et al., 2009) highlights many bands. Supplemental Table S-3 lists, from the proteins observed, those first predicted by SignalP 3.0 to be secreted and then by the NetNGlyc server (Blom et al., 2004) to be potentially glycosylated. The table lists 41 candidate glycoproteins. Interestingly, protein MM0002 was not predicted by SignalP to contain a signal peptide, although it is a candidate for leaderless secretion by SecretomeP, and NetNGlyc does suggest 2 Asn sites as potentially glycosylated. Hence, the list of potentially $N$-glycosylated proteins can be longer, should proteins secreted leaderlessly also be considered. The predictions from SignalP version 4.0 comprise a subset of the version 3.0 predictions. All but two of the proteins absent from the newer algorithm's list of signal peptide-containing sequences (MM1329 and MM2033) are also candidates for leaderless secretion (according to the SecretomeP algorithm), and thus potentially $N$-glycosylated. Additional glycoproteins likely await discovery.

It should also be clarified that the tandem MS conditions and protein quantities required for high-throughput peptide identification differ from those employed in oligosaccharide and glycoprotein analysis. Glycoprotein analyses will employ 10-100 fold more material and the MS/MS conditions will be customized for each analyte.

The utility of data mining is that, by employing a relatively simple enrichment method without exhaustive chromatographic purifications, these four proteins (MM0002, MM0716, MM1364, and MM1976) were revealed as glycosylated and bearing at least hexose and $\mathrm{N}$-acetylhexosamine saccharides. It also indicates how glycopeptide knowledge can be extracted from tandem mass spectrometry data, even without upstream enrichment, bonus knowledge when experiments are not specifically targeting glycosylation. Adding chromatographic dimensions will increase the number of glycopeptides detected, because glycopeptide intensities are often suppressed by co-eluting non-glycopeptides, and because the chromatographic conditions that best resolve different glycopeptides differ from those best resolving peptides, in general. Analyses probing more $M$. mazei glycopeptides and at greater depth are underway.

\section{PREDICTION OF ARCHAEAL PROTEIN $\boldsymbol{N}$-TERMINI}

Signal peptides are key participants in protein translocation, but our ability to predict them confidently, especially for archaeal species, has been limited by availability of experimental data (Armengaud, 2009). Even among bacteria, e.g., Mycobacterium smegmatis, predictions were found to be erroneous for up to $19 \%$ of protein $N$-termini (Gallien et al., 2009). Complications delineating open reading frames (ORFs) arise when multiple AUG codons lie near the DNA 5' end (ambiguity that often prompts annotators to select the longest open reading frame) (Prats et al., 1992; Kozak, 1997; Meinnel and Giglione, 2008; Fournier et al., 2012), when organisms employ alternative initiation codons; e.g., GUG or UUG (Klunker et al., 2003; Falb et al., 2006; Yamazaki et al., 2006; Meinnel and Giglione, 2008; Running and Reilly, 2009; Elzanowski and Ostell, 2013), or when translation initiates at multiple sites (Prats et al., 1992). Modifications to $N$-termini are rarely predictable, and their prevalence varies with organism. Strikingly, $14-19 \%$ of protein $N$-termini in 
Table 1 | proteins detected by two or more peptides from concanavalin A eluate.

\begin{tabular}{|c|c|c|c|c|c|c|c|c|}
\hline $\begin{array}{l}\text { Uniprot } \\
\text { accession }\end{array}$ & MM\# & Name & $\begin{array}{c}\text { Unique peptides } \\
\text { observed }\end{array}$ & $\begin{array}{c}\text { Mascot } \\
\text { protein score }\end{array}$ & Exprot $^{\mathrm{a}}$ & SignalP ${ }^{b}$ & SecPc & LipoPd \\
\hline Q800X9 & MM0001 & Dipeptide ABC transporter & 5 & 229 & 1 & & Y & \\
\hline Q800S0 & MM0066 & Hypothetical protein & 5 & 216 & 2 & Y & Y & \\
\hline Q800K8 & MM0128 & Lon protease, membrane-bound & 8 & 276 & & & & \\
\hline Q8Q0F2 & MM0184 & $\mathrm{Rps} 3 \mathrm{Ae}$ & 2 & 51 & & & & \\
\hline Q8PZ66 & MM0628 & $\begin{array}{l}\text { Methylenetetrahydromethanopterin } \\
\text { reductase }\end{array}$ & 6 & 276 & & & & \\
\hline Q8PZ61 & MM0633 & Multiheme cytochrome $c$, hypothetical & 2 & 90 & & & Y & \\
\hline Q8PZ47 & MM0647 & Oligosaccharyl transferase & 2 & 91 & & & Y & \\
\hline Q8PYZ8 & MM0700 & HppA & 3 & 39 & & $Y^{*}$ & Y & \\
\hline Q60184 & MM0782 & AtpC & 4 & 154 & & & & \\
\hline Q60183 & MM0783 & AtpE & 4 & 34,13 & & & & \\
\hline F1SVJ4 & MM0784 & AtpK & 5 & 365 & 1 & $Y^{*}$ & Y & \\
\hline O59659 & MM0785 & Atpl & 4 & 115 & & & Y & \\
\hline Q8PYS4 & MM0786 & AtpH & 2 & 75 & & & & \\
\hline Q8PYJ5 & MM0866 & Periplasmic serine protease & 4 & 242 & 1 & & Y & \\
\hline Q8PYIO & MM0882 & Hypothetical protein & 3 & 106 & & & Y & \\
\hline Q8PYE0 & MM0922 & Eif5a, IF5A & 2 & 131 & & & & \\
\hline Q8PY73 & MM0991 & Thioredoxin & 5 & 150 & 2 & Y & & Y \\
\hline Q8PY52 & MM1012 & Rpl1P & 3 & 62 & & & & \\
\hline Q8PY39 & MM1025 & ThiC & 3 & 58 & & & & \\
\hline Q8PXW0 & MM1106 & Putative phosphoserine phosphatase & 5 & 81 & & & & \\
\hline Q8PXV8 & MM1108 & $\begin{array}{l}\text { Mtd, F420-dependent } \\
\text { methylenetetrahydromethanopterin } \\
\text { dehydrogenase }\end{array}$ & 3 & 126 & & & & \\
\hline Q8PXI2 & MM1236 & HtpX protease & 2 & 25 & & Y & Y & \\
\hline Q8PXH8 & MM1240 & Methyl CoM reductase, alpha subunit & 7 & 237 & & & & \\
\hline Q8PXH7 & MM1241 & Methyl CoM reductase, gamma subunit & 10 & 563 & & & & \\
\hline Q8PXH4 & MM1244 & Methyl CoM reductase, beta subunit & 13 & 467 & & & & \\
\hline Q8PXG8 & MM1250 & Cation transporter & 2 & 66 & & $Y^{*}$ & Y & \\
\hline Q8PXG7 & MM1251 & Cation transporter & 2 & 109 & & $Y^{*}$ & Y & \\
\hline Q8PX89 & MM1333 & Zinc $A B C$ transporter & 10 & 486 & 2 & Y & & Y \\
\hline Q8PX82 & MM1340 & Pyruvate synthase, alpha subunit & 2 & 61 & & & & \\
\hline Q8PX60 & MM1362 & Putative aliphatic sulfonate binding & 11 & 556 & 2 & Y & Y & \\
\hline Q8PX58 & MM1364 & S-layer paralog & 28 & 1093 & 1 & Y & Y & \\
\hline Q8PX43 & MM1379 & Thermosome, alpha subunit & 10 & 329 & & & & \\
\hline Q8PWZ8 & MM1424 & SecF & 2 & 85 & 1 & Y & Y & \\
\hline Q8PWZ7 & MM1425 & SedD & 3 & 144 & & Y & Y & \\
\hline Q8PWX0 & MM1456 & USP-like & 4 & 153 & & & & \\
\hline P80650 & MM1540 & $\mathrm{MtrH}$ & 9 & 276 & & & & \\
\hline P80656 & MM1541 & MtrG & 4 & 192 & & & Y & \\
\hline P80654 & MM1542 & MtrF & 2 & 105 & & & Y & \\
\hline O59640 & MM1543 & MtrA & 6 & 309 & & & & \\
\hline
\end{tabular}


Table 1 | Continued

\begin{tabular}{|c|c|c|c|c|c|c|c|c|}
\hline $\begin{array}{l}\text { Uniprot } \\
\text { accession }\end{array}$ & MM\# & Name & $\begin{array}{c}\text { Unique peptides } \\
\text { observed }\end{array}$ & $\begin{array}{l}\text { Mascot } \\
\text { protein score }\end{array}$ & Exprot $^{a}$ & SignalPb & SecPc & LipoPd \\
\hline P80655 & MM1544 & MtrB & 4 & 222 & & & Y & \\
\hline 059638 & MM1545 & MtrC & 5 & 127 & & & Y & \\
\hline P80653 & MM1546 & MtrD & 2 & 133 & & Y & Y & \\
\hline P80651 & MM1547 & MtrE & 4 & 117 & & Y & Y & \\
\hline Q8PWN5 & MM1549 & $\mathrm{Na} /$ proline symporter & 4 & 211 & & $Y^{*}$ & Y & \\
\hline Q8PWN3 & MM1551 & Hypothetical protein & 4 & 75 & 1 & Y & Y & \\
\hline Q8PWM3 & MM1561 & $\mathrm{ABC}$ transporter, tungsten binding protein & 2 & 72 & & $Y^{*}$ & Y & \\
\hline Q8PWJ6 & MM1589 & Surface layer protein B & 3 & 128 & 1 & Y & Y & \\
\hline Q8PWE2 & MM1647 & MtaB1 & 14 & 357 & & & & \\
\hline Q8PWE1 & MM1648 & MtaC1 & 10 & 533 & & & & \\
\hline Q8PWA1 & MM1695 & Hypothetical protein & 10 & 425 & 2 & Y & Y & Y \\
\hline Q8PW83 & MM1713 & Hypothetical protein & 2 & 173 & & & Y & \\
\hline Q8PW41 & MM1760 & Rps $2 p$ 30S ribosomal protein S2 & 3 & 104 & & & Y & \\
\hline Q8PW15 & MM1789 & Hypothetical protein & 2 & 64 & & & Y & \\
\hline Q8PVY9 & MM1816 & Conserved protein & 6 & 238 & 1 & Y & Y & \\
\hline Q8PVW4 & MM1843 & HdrE, heterodisulfide reductase & 6 & 210 & & Y & Y & \\
\hline Q8PVV1 & MM1859 & DdpA, ABC transporter & 3 & 29 & 1 & Y & Y & \\
\hline Q8PVM4 & MM1939 & Glutamine binding protein & 2 & 115 & 2 & Y & & Y \\
\hline Q8PVI7 & MM1976 & S-layer protein, (identified) & 151 & 5310 & 1 & Y & Y & \\
\hline Q8PVI6 & MM1977 & Hypothetical protein & 3 & 118 & 2 & Y & Y & Y \\
\hline Q8PVG6 & MM1999 & Hypothetical protein & 4 & 103 & 2 & Y & Y & Y \\
\hline Q8PVG5 & MM2000 & Hypothetical protein & 4 & 82 & 2 & Y & Y & Y \\
\hline Q8PVD2 & MM2033 & Stomatin-like protein & 2 & 52 & & $Y^{*}$ & & \\
\hline Q8PVA2 & MM2069 & Iron III dicitrate binding protein & 5 & 179 & 2 & Y & Y & Y \\
\hline Q8PV27 & MM2147 & $\operatorname{Sec} Y$ & 2 & 67 & & & Y & \\
\hline Q8PV17 & MM2157 & Rpsllp, 30S ribosomal protein S11p & 2 & 81 & & & Y & \\
\hline Q50227 & MM2171 & $\begin{array}{l}\text { Cytochrome } b, \text { F420 non-reducing } \\
\text { hydrogenase II }\end{array}$ & 2 & 87 & & & Y & \\
\hline Q8PUU5 & MM2234 & Hypothetical protein & 2 & 94 & 1 & Y & Y & \\
\hline $\begin{array}{l}\text { Q8PUR8/ } \\
\text { AAM31960 }\end{array}$ & MM2264 & Ef1A & 10 & 301 & & & & \\
\hline Q8PUM8 & MM2305 & $\mathrm{Na} /$ proline symporter & 2 & 51 & & Y & Y & \\
\hline Q8PUL4 & MM2320 & EchA & 3 & 75 & & $Y^{*}$ & Y & \\
\hline Q8PU81 & MM2460 & Dipeptide oligopeptide binding protein & 16 & 556 & 2 & Y & Y & Y \\
\hline F1SVE1 & MM2479 & FpoO, F42OH2 dehydrogenase & 2 & 83 & & & & \\
\hline F1SVH9 & MM2481 & FpoM, F420H2 dehydrogenase & 2 & 63 & & Y & Y & \\
\hline F1SVK0 & MM2482 & FpoL, F420H2 dehydrogenase & 2 & 91 & & Y & Y & \\
\hline F1SVE0 & MM2483 & FpoK, F420H2 dehydrogenase & 2 & 64 & & Y & Y & \\
\hline Q8PU59 & MM2487 & $\mathrm{FpoH}, \mathrm{F} 42 \mathrm{OH} 2$ dehydrogenase & 3 & 97 & & $Y^{*}$ & Y & \\
\hline P27094 & MM2505 & DnaK, chaperone protein & 13 & 451 & & & & \\
\hline Q8PU26 & MM2531 & Hypothetical protein & 3 & 113 & 1 & & Y & \\
\hline Q8PTZ0 & MM2567 & $\begin{array}{l}\text { ABC transporter, periplasmic binding } \\
\text { protein }\end{array}$ & 14 & 420 & 2 & Y & & \\
\hline Q8PTY1 & MM2576 & Ferrous iron transport protein B & 8 & 276 & & & Y & \\
\hline Q8PTS5 & MM2637 & Ion channel transporter & 3 & 58 & & & Y & \\
\hline Q8PTQ7 & MM2656 & Peptidyl-prolyl cis-trans isomerase & 2 & 28 & & & & \\
\hline Q8PTI7 & MM2728 & Hypothetical protein & 2 & 61 & 1 & $Y^{*}$ & Y & \\
\hline Q8РT25 & MM2893 & Hypothetical protein & 6 & 193 & 1 & Y & Y & \\
\hline Q8PSQ2 & MM3024 & Hypothetical protein & 3 & 65 & 1 & Y & Y & \\
\hline Q8PS84 & MM3198 & Lipoprotein, hypothetical & 5 & 134 & & & & \\
\hline
\end{tabular}

${ }^{a}$ Exprot (Saleh et al., 2010); 1, Predicted type I signal peptidase substrate; 2, Predicted type /l signal peptidase substrate.

b SignalP (Bendtsen et al., 2004b); Y, Predicted signal peptide by SignalP 3.0

${ }^{c}$ SecP (Bendtsen et al., 2004a, 2005); Y, Predicted substrate for leaderless secretion by SecretomeP 2.0.

¿ LipoP (Juncker et al., 2003); Y, Predicted lipoprotein.

*Predicted as secreted only by the SignalP eukaryotic predictor. 
halophiles Halobacterium salinarum and Natronomonas pharaonis are acetylated (Falb et al., 2006). Clearly, experimentally characterizing the $\mathrm{N}$-termini of microbial proteins is important.

In a computational approach, SignalP 3.0 (Bendtsen et al., 2004b), LipoP (Juncker et al., 2003), and SecretomeP 2.0 (Bendtsen et al., 2004a, 2005) algorithms were employed to predict secreted proteins, while Exprot predictions for M. mazei Gö1 were obtained from Supplemental information in Saleh et al. (2010). SignalP used gram-positive, gram-negative, and eukaryotic-type models, while SecretomeP was applied employing bacterial models (Bendtsen et al., 2004a, 2005). Predictions for proteins recovered by Con A binding are displayed in Supplemental Table S-2. Predicted and experimental results are compared in the following section and indicate a tendency of prediction algorithms to over-predict signal peptide excision.

\section{EXPERIMENTALLY DETECTED $\boldsymbol{N}$ - AND $\boldsymbol{C}$-TERMINI}

Clearly, experimental approaches tailored to recovering as many $N$-terminal peptides as possible (Ogorzalek Loo et al., 2002; Gevaert et al., 2003; Dormeyer et al., 2007; Shen et al., 2007; Russo et al., 2008; Yamaguchi et al., 2008; Gallien et al., 2009; Xu and Jaffrey, 2010; Fournier et al., 2012; Kim et al., 2013; Venne et al., 2013) provide large datasets for evaluating and enhancing prediction algorithms and improving protein database annotations. Nevertheless, datasets acquired by other experimental approaches with different goals can be harvested to yield equivalent information for a smaller number of proteins, some of which are missed by large-scale "terminalomics" studies, especially because many large-scale approaches recover only free amino termini. Data harvests are also more likely to reveal instances where multiple $N$-terminal forms are present (e.g., modified and unmodified).

Information about protein $\mathrm{N}$-termini is not automatically returned by database searching algorithms. Although most algorithms now consider both excised and retained initiator methionines when attempting to match MS/MS spectra, $N$-terminal acetylation is only considered if specified in the search parameters. Because each variable modification (i.e., one which may be present or absent) that must be considered in the search process adds to the time required for completion and often reduces specificity, only abundant variable modifications are usually considered by high-throughput proteomics studies.

From our Con A eluate studies, some LC-MS/MS spectra spanned M. mazei protein $N$ - or $C$-termini, allowing us to compile that information in Table 2. M. acetivorans $\mathrm{C} 2 \mathrm{~A}$ and M. mazei Gö1 $N$ - and $C$-termini information obtained previously (Francoleon et al., 2009), are also included. Information was recovered by semi-tryptic and error-tolerant searches. Semitryptic searches seek matches for MS/MS spectra to peptides in which only one terminus matches trypsin's known cleavage specificity. Examples may include (i) peptides with non-Lys or Arg $C$-termini, but with $N$-termini reflecting cleavage after Lys or Arg, or (ii) peptide $N$-termini inconsistent with cleavage after Lys or Arg, but with $C$-terminal Lys or Arg. Error-tolerant searches, described in the Introduction, consider a large range of potential modifications.

Of M. mazei protein $N$-termini recovered by concanavalin A binding, only S-layer protein MM1976 underwent signal peptide excision. These experimental results contrasted with those from prediction algorithms SignalP 3.0 (Bendtsen et al., 2004b) and Exprot (Saleh et al., 2010), which were found to over-predict the presence of signal peptides. Although SignalP 3.0 correctly predicted the MM1976 signal peptide, it also predicted leaders for 7 other proteins, while Exprot predicted signal peptides for 6 other proteins (Supplemental Table S-2). The newer algorithm SignalP 4.0 predicted leaders for only MM1362 and MM1547, in addition to MM1976. The poor correlation between prediction and experiment underscores previous conclusions about major problems predicting proteins lacking signal peptides (Antelmann et al., 2001).

Interestingly, SecretomeP 2.0, a machine-learning approach developed to predict non-classically secreted proteins in mammals and bacteria; i.e., proteins exported without a classical $N$-terminal signal peptide, predicted leaderless secretion of 14 proteins in Supplemental Table S-2 (Bendtsen et al., 2004a). Overlap for 8 of these SecretomeP 2.0 predictions with those by SignalP 3.0 is reasonable, because SecretomeP was trained on datasets of secreted protein sequences that had their signal peptides deleted. Detection of the other six proteins (MM0866, MM1009, MM1075, MM1221, MM1542, and MM1362) by our study would seem to verify these SecretomeP predictions.

M. mazei $N$-terminal peptides were recovered from 28 proteins over the course of this and previous studies. These protein identifications were supported by MS/MS spectra from multiple peptides in all but 3 cases. (Observing multiple peptides from a protein is one criterion for assessing confidence in the protein's identification.) Table 2 also includes data for $3 \mathrm{M}$. acetivorans $N$-termini. Heterogeneous $N$-termini were observed from 4 of the 31 proteins; e.g., Acetyl-VDAASTGLFLDAAGMK and Acetyl-MVDAASTGLFLDAAGMK were observed from $\mathrm{A}_{1} \mathrm{~A}_{0}$ $\mathrm{H}^{+}$ATPase subunit $\mathrm{K}$ (MM0784), indicating partial methionine excision prior to acetylation. MM0784 matched predictions in all other respects; the 4 tryptic peptides observed verified $100 \%$ of the $8-\mathrm{kDa}$ proteolipid's sequence. Strong $b_{1}$ ions (i.e., peptide fragments corresponding to protonated Ac-Val $-\mathrm{H}_{2} \mathrm{O}$ or protonated Ac-Met $-\mathrm{H}_{2} \mathrm{O}(\mathrm{m} / z 142.09$ and 174.06, respectively) in the MS/MS spectra confirmed the modification as $N$-acetylation (Yalcin et al., 1995). Because $b_{1}$ ions are generally observed in MS/MS spectra of $N$-terminally acetylated peptides, but otherwise relatively rare, their presence provides powerful validation of the modified peptide that is independent of the statistical score; i.e., search algorithms do not accord special significance to $b_{1}$ ions.

Partial methionine processing has been noted in other archaeal species (Falb et al., 2006). That the $N$-terminus of the $A_{1}$ ATPase proteolipid subunit was found to be blocked was not surprising; blocked $N$-termini have frequently been observed for $\mathrm{F}_{0}$ proteolipids; e.g., $N$-formylmethionine in bacteria (E. coli and Bacillus, UniProt Accessions P68699 and P00845, respectively), yeast mitochondria (Sebald et al., 1979), and wheat (Howe et al., 1982) and spinach (P69447) chloroplasts.

Putative regulatory protein MM1075 (MtaR) was detected as M.SENAGTSTVIVDK (where M.S denotes methionine excision) and a formylated version, M.SENAGTSTVIVDK, modified at $S 7$ or T8. MS/MS spectra revealed ions $y_{1}-y_{5}$, and $y_{7}-y_{11}$, localizing the modification to $S 7$ or $T 8$. (See Figure 1). Technically, $T \rightarrow E$, 
Table 2 | M. mazei and $M$. acetivorans protein termini recovered.

\begin{tabular}{|c|c|c|c|c|}
\hline Accession & MM\# & Protein & $\mathrm{N}$-Termini & C-Termini \\
\hline Q80024 & MM0314 & Valyl tRNA synthase & & GAVVVIVR.- \\
\hline Q8PZ47 & MM0647 & Oligosaccharyl transferase & & E.EAVLNGQEIKI.- \\
\hline F1SVJ4 & MM0784 & AtpK, $A_{1} A_{0} H+$ ATPase subunit & $\begin{array}{l}\text { Ac-VDAASTGLFLDAAGMK.A and } \\
\text { Ac-MVDAASTGLFLDAAGMK.A }\end{array}$ & K.GLILTVIPETIVIFGLVVALLINQ.- \\
\hline Q8PYJ5 & MM0866 & Periplasmic serine protease & -.MNDENVNSDGVDSK.N & \\
\hline Q8PY77 & MM0987 & Conserved protein & & R.AGQFNNASAENTCAEHEHHH.- \\
\hline Q8PY73 & MM0991 & Thioredoxin & & R.AILYHENVNK.- \\
\hline Q8PY70 & MM0994 & Precorrin-8X mutase & & E.LVAIARESEE.- \\
\hline Q8PY55 & MM1009 & SecE & M.VESALEPNITTK.S & \\
\hline Q8PXZ1 & MM1075 & Putative regulatory protein & M.SENAGTSTVIVDK.T & \\
\hline Q8PXZ1 & MM1075 & Putative regulatory protein & $\begin{array}{l}\text { M.SENAGTSTVIVDK.T + Formyl or } \\
\text { T8 } \rightarrow \text { E8 }\end{array}$ & \\
\hline Q8PXX0 & MM1096 & Thermosome, gamma & M.AAQPIFILRE.G & \\
\hline Q8PXV8 & MM1108 & Mtd, F420-dependent & M.VNIGFIK.M & \\
\hline Q8PXJ7 & MM1221 & Mc1 chromosomal protein & M.SNTRNFVLRDEEGNE.H & \\
\hline Q8PXH8 & MM1240 & $\begin{array}{l}\text { Methyl CoM reductase, alpha } \\
\text { subunit }\end{array}$ & Ac-AADIFSK.F & E.RSLIIPAK.- \\
\hline Q8PXH4 & MM1244 & $\begin{array}{l}\text { Methyl CoM reductase, beta } \\
\text { subunit }\end{array}$ & M.SDTVDIYDDRGK.L & G.DVFGSIDEFROPIKAVAGAL.- \\
\hline Q8PXG8 & MM1250 & Cation transporter & & R.LGLPLGLVAMTIYFIVLFILKI.- \\
\hline P80650 & MM1540 & $\mathrm{MtrH}$ & $-. M F K F D K K Q E V F E . L$ & \\
\hline P80650 & MM1540 & $\mathrm{MtrH}$ & $\begin{array}{l}\text { Supposed internal peptide } 232-239 \\
\text { observed after trypsin M.ASAWDWLR.K }\end{array}$ & \\
\hline P80654 & MM1542 & MtrF & $\begin{array}{l}\text { M.AEEHEKGVPMVLAPQMGAI.D (Asp-N } \\
\text { product) }\end{array}$ & \\
\hline O59640 & MM1543 & MtrA & M.ADKREPAPGWPILKGEYEVG.D & K.VEGAMIGLTITISLLGLLLLGR.- \\
\hline P80655 & MM1544 & MtrB & M.SIVRIAPE.I & \\
\hline O59638 & MM1545 & $\mathrm{MtrC}$ & & R.DAYAVVGTGLLPSAEELQ.- \\
\hline P80653 & MM1546 & MtrD & & K.AVISSVVASILCCAIVAVIAIAOLGGI.- \\
\hline P80651 & MM1547 & MtrE & -.MEPLIGMGVLAL.I & K.AYGPYKEDKAEEASA.- \\
\hline Q8PWE2 & MM1647 & MtaB1 & M.AATRFTKMAYASADE.M & K.VFLPENYGF.- \\
\hline Q8PWE1 & MM1648 & MtaC1 & $. M L D F T E A S L K K . V$ & \\
\hline Q8PVI7 & MM1976 & S-layer protein & (signal pept).ADVIEIR.G & \\
\hline Q8PVI7 & MM1976 & S-layer protein & ADVIEIR.G +14 Da & \\
\hline Q8PVI7 & MM1976 & S-layer protein & $. X A D V I E I R . G X=40 \mathrm{Da}$ & \\
\hline Q8PVI7 & MM1976 & S-layer protein & $. X A D V I E I R . G X=42 \mathrm{Da}$ & \\
\hline $\begin{array}{l}\text { Q50226* or } \\
\text { Q8PUM1** }\end{array}$ & $\begin{array}{l}\text { MM2170* or } \\
\text { MM2313* }\end{array}$ & $\begin{array}{l}\text { F420 non-reducing } \\
\text { hydrogenase }\end{array}$ & M.VNVTVDPLTR & \\
\hline Q8PUR8 & MM2264 & Ef1A & M.AADKPHMNLAVIGHIDHGK.S & \\
\hline
\end{tabular}


Table 2 | Continued

\begin{tabular}{lllll}
\hline Accession & MM\# & Protein & N-Termini & C-Termini \\
\hline Q8PUL4 & MM2320 & EchA & M.AQLAKFDVPEELTNKALE.A & K.LTTLGYAISIILIVIALAGGVL.- \\
Q8PU74 & MM2467 & Rpl7ae & .MLPVASLLILVPLIFAVVTFFTK.T & K.IQTGVVQTYATALIAGVSLLIILVKLIMEVL.- \\
F1SVH9 & MM2481 & FpoM & M.TAIPLTFYLGLAALLFSIGLYGVMTHK.S & L.DELNILRW.- \\
F1SVK0 & MM2482 & FpoL & E.DPWLNLSGVYERK.- \\
F1SVE0 & MM2483 & FpoK & & \\
Q8PTZ0 & MM2567 & ABC transporter, periplasmic & & \\
& & binding protein & -MLDFTEASLKK.V & \\
Q9C4S2 & MA0456 & Co-methyl transferase & Ac-MLDFTEASLKK.V & R.LPVYYGKEEV.- \\
Q9C4S2 & MA0456 & Co-methyl transferase & (signal pept).VDVIEIR.G & K.VALNIMK.- Ox \\
Q8TSG7 & MA0829 & S-layer protein & R.KTEVETIPAAAPAPAAA.- \\
Q8TSG7 & MA0829 & S-layer protein & .XVDVIEIR.G X=42 Da & R.AYPEYLMREE.- \\
Q8TRS7 & MA1092 & Ribosomal protein S5 & M.TNTEIFEK.L & R.TSYGFOPK.- \\
P58868 & MA2971 & Corrinoid protein & & \\
Q8TKI9 & MA3416 & Ribosomal protein S3Ae & & \\
O8TIE5 & MA4207 & Ammonium transporter & & \\
Q8THH0 & MA4547 & Methyl CoM reductase, & & \\
& & gamma subunit & & \\
\hline
\end{tabular}

*Several LC-MS/MS experiments were unable to differentiate between the two proteins; none of the 6 peptides identified was unique.

Red entries correspond to identifications based on a single peptide.
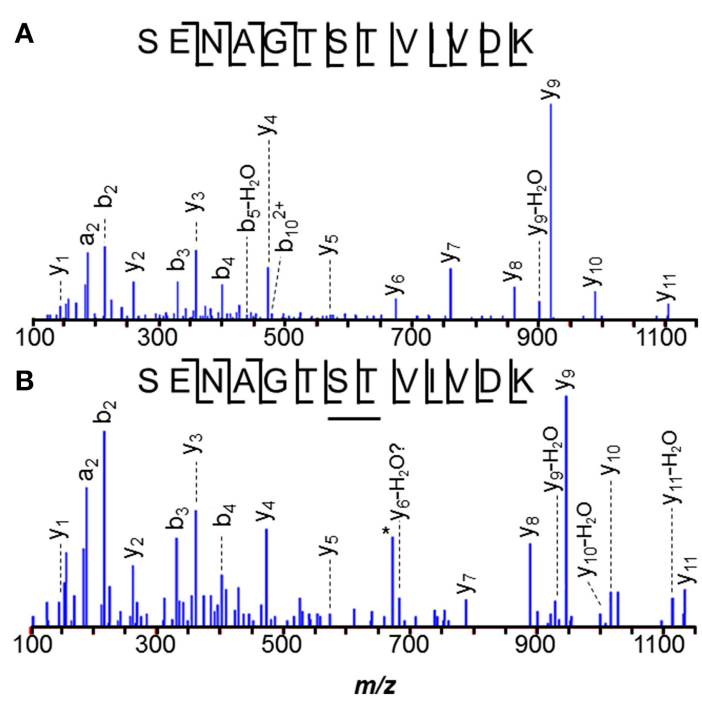

FIGURE 1 | $\boldsymbol{N}$-terminal peptide of $\boldsymbol{M}$. mazei MM1075 (MtaR). (A) unmodified, and (B) $O$-formylated at $\mathrm{Ser}_{7}$ or $\mathrm{Thr}_{8}$. Unidentified $\mathrm{m} / \mathrm{z} 673$, * lies $1 \mathrm{Da}$ below the predicted $\mathrm{m} / \mathrm{z}$ for unmodified $\mathrm{y}_{6}$.

or $S \rightarrow D$ substitutions or $\mathrm{C}_{2} \mathrm{H}_{4}$ addition would also match the incremented mass, but the multiple base substitutions required to convert a Thr (ACC codon) to Glu (GAA/GAG) or a Ser (UCU) to Asp (GAU/GAC) are not easily reconciled, leading us to favor interpretation as formylation. High mass accuracy measurements can distinguish addition of $\mathrm{CO}$ (formylation) from $\mathrm{C}_{2} \mathrm{H}_{4}(27.995$ vs. $28.031 \mathrm{Da})$.

O-formylation may be important to controlling MM1075's function, adapting cells to acetate- and methanol-dependent growth. It's mRNA levels are 200-500 times higher in methanol- vs. trimethylamine-grown cells, and still higher for acetate culture (Hovey et al., 2005; Krätzer et al., 2009), while the operon's other genes, MM1073 and MM1074, are among the most highly regulated genes known in the Archaea (Bose et al., 2006). It will be interesting to monitor modifications of MM1075 as culture conditions are varied. For example, evidence that the ratio of formylated:unformylated MM1075 varies with; e.g., substrate or with length of time since the substrate was switched, would support a role in adaptation for the modification.

\section{SURFACE LAYER PROTEIN MODIFICATIONS}

The M. mazei sheath or S-layer protein, MM1976, is one of the most abundant proteins made by the cell (Francoleon et al., 2009; Rohlin et al., 2012). Con A binding enriched cell lysates for this protein, permitting characterization of low stoichiometry modifications. $N$-termini for the $S$-layer protein were especially varied, although all were consistent with signal peptide cleavage after residue 24 . By abundance, the major $N$-terminal peptide observed was ADVIEIR, although peptides 14, 40, and 42 Da heavier were also found. The modified peptides followed ADVIEIR in elution by $<1,8$, and $3 \mathrm{~min}$, respectively.

$N$-terminal addition of $42 \mathrm{Da}$, localized by $y_{1}-y_{6}$ and $b_{2}$ ions, (see Francoleon et al., 2009, Figures 3C,D) was initially attributed to $\alpha$-amino acetylation. However, none of the tandem mass spectra acquired for this precursor yielded a $b_{1}$-ion, generally considered diagnostic of $N$-terminal acetylation (Yalcin et al., 1995). Careful mass measurements on $b_{2}$ product ions better matched modifications of composition $\mathrm{C}_{2} \mathrm{H}_{2} \mathrm{O}$, rather than $\mathrm{C}_{3} \mathrm{H}_{6}$. The M. acetivorans ortholog, MA0829, also displayed evidence of signal peptide cleavage, yielding the $N$-terminal tryptic peptides VDVIEIR and a $+42 \mathrm{Da}$ variant, similarly lacking its $b_{1}$ product ion by MS/MS (Francoleon et al., 2009 see Francoleon et al., 2009, Figures 3A,B). Further investigation is required to 
confidently ascribe $N$-terminal modifications for these low abundance variants.

MS/MS spectra suggest that the $M$. mazei +40 Da modification also localizes to the $N$-terminus, as $y_{1}-y_{6}, a_{2}$, and $b_{2}-b_{5}$ ions were observed. Again, the $b_{1}$-ion was not seen. The late elution of the +40 Da species relative to unmodified ADVIEIR, leads us to questions whether it might arise from in-source collision-induced dissociation (CID) of an exceptionally labile, hydrophobic group, leaving behind only a residual $-\mathrm{N}=\mathrm{CH}-\mathrm{CH}=\mathrm{O},-\mathrm{N}=$ $\mathrm{C}\left(\mathrm{CH}_{3}\right)_{2}$, or $-\mathrm{N}=\mathrm{CH}-\mathrm{CH}_{2}-\mathrm{CH}_{3} \mathrm{~N}$-terminus. Available mass accuracy narrowed consideration to the latter two possibilities. As an alternative to production by $\mathrm{CID}$, the $\mathrm{C}_{3} \mathrm{H}_{4}$ increment could correspond to a Schiff base formed by addition of propionaldehdye, although the mechanism for such a modification is unclear. Further effort is required to characterize this $\mathrm{C}_{3} \mathrm{H}_{4}$ modification.

In some MM1976 ADVIEIR peptides, Glu 5 was incremented by $14 \mathrm{Da}$, consistent with methyl esterification. Elsewhere, artifactual methyl adducts were attributed to incubation in acidic methanol during gel fixation or staining (Parker et al., 1998; Xing et al., 2008). Here the analyses displaying the modification were performed on proteins digested in solution; i.e., not subjected to staining. Their only exposure to methanol was shorter, at lower concentration and at lower temperature than conditions known to esterify. Thus, the $14 \mathrm{Da}$ adducts are unlikely to be artifacts. Other instances of relevant methyl esters have been described previously (Hoelz et al., 2006).

\section{OTHER MODIFIED PROTEINS}

The predicted $N$-terminal peptide for MM1540, subunit $H$ of tetrahydrosarcinopterin $S$-methyl transferase (MtrH) was confirmed to be MFKFDKKQE. Interestingly, peptide $M$. ASAWDWLR (residues 232-239) was also observed, potentially reflecting protein processing, anomalous cleavage, or alternate initiation, although we could find no rationalization for the latter possibility. That MM1540 is the catalytic subunit of the $S$-methyl transferase and binds methyl tetrahydrosarcinopterin (Hippler and Thauer, 1999) encourages speculation that an inadvertent methyl transfer to $\mathrm{Met}_{231}$ instead of the coenzyme $M$ thiol might lead to a sulfonium-activated cyanogen bromide-like cleavage at the observed position.

The $N$-terminal peptide of $M$. acetivorans C2A MA0456 (MtaC1, methanol-5-hydroxybenzimidazolyl cobamide comethyl transferase) was previously recovered as MLDFTEASLK and in its methionine sulfoxide form. Methionines are often oxidized under experimental conditions. A related peptide 58-Da heavier than the unmodified species was also observed (Figure 2). Tandem MS of the latter peptide localized the +58 - Da to the first residue, revealing intense 190- and 126-Da product ions, consistent with the $b_{1}$ ion from an $N$-terminally acetylated peptide and a corresponding 64-Da neutral loss product, unique to methionine sulfoxide. As discussed earlier, $b_{1}$ observations strongly suggest $N$-terminal acetylation. Larger $b$-ions also showed 64-Da neutral loss products, establishing the variant $M$. acetivorans peptide as Ac-M ${ }^{\text {ox }}$ LDFTEASLK. Peptide Ac-M ${ }^{\text {ox }}$ LDFTEASLKK, was also observed. Previous mass analyses of intact $M$. acetivorans proteins reported only the

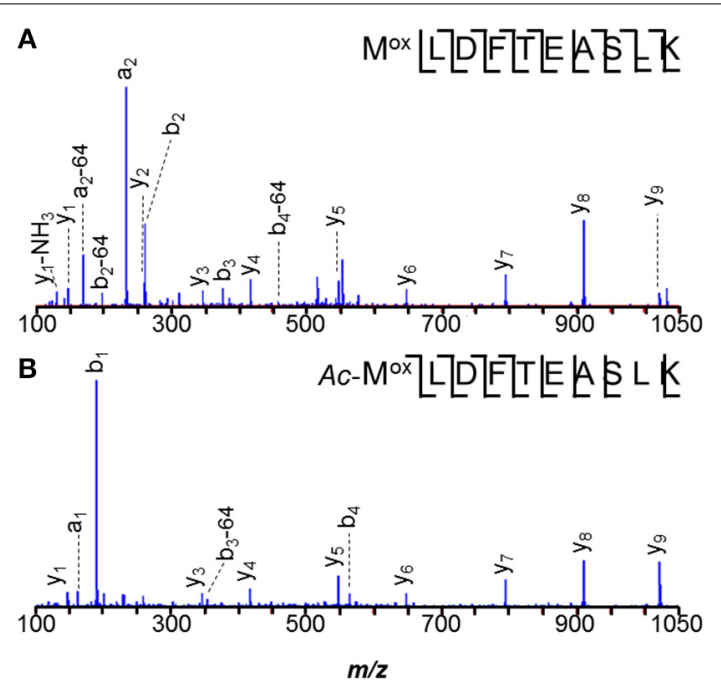

FIGURE 2 | $\boldsymbol{N}$-terminal peptides of $\boldsymbol{M}$. acetivorans MA0456 (MtaC1). (A) Unmodified MLDFTEASLK, (B) Low abundance variant Ac-M ${ }^{\circ}$ LDFTEASLK. Intense $190-\mathrm{Da}$ ions correspond to the $b_{1}$ product from the $\mathrm{N}$-terminally acetylated peptide. Larger $b$-ions show 64-Da neutral loss products characteristic of methionine sulfoxide. [Based on its measured mass, the product ion observed at $m / z 129.11$ is attributed to $y_{1}-\mathrm{H}_{2} \mathrm{O}(m / z 129.10)$, rather than unmodified $b_{1}(\mathrm{~m} / z$ 129.01)].

free amino terminal form (Patrie et al., 2006). Interestingly, we observed only non-acetylated MLDFTEASLK from the M. mazei ortholog, MM1648, despite the larger protein quantity available for analysis. Note that M. mazei initiates translation 10 residues downstream of the originally annotated position) (Deppenmeier et al., 2002).

Careful data mining revealed additional modifications to MA0456 (MtaC1). Three versions of peptide 149-159 were found: ANGYDVVDLGR, the $\mathrm{Asn}_{2}$ deamidated peptide, and a peptide 42-Da heavier than predicted, with its modification localized to the first residue by $y_{10}$ and $b_{2}$ ions (Figure 3 ). The absence of a $b_{1}$-ion and accurate mass measurement ruled out $N^{\alpha}$ acetylation for the heavier peptide, but could support an $A \rightarrow I / L$ substitution or $N^{\alpha}$-trimethylation. However, amino acid substitution is hard to rationalize from the nucleotides coding Ala (GCA) vs. those coding Leu/Ile (CTX, TTA, TTG/ATT, ATC, ATA), as is sub-stoichiometric substitution. $N^{\alpha}$-trimethylation would require prior cleavage of the protein to expose $\mathrm{N}$ terminal ANGYDVVDLGR for modification. Interestingly, the peptide lies near $\mathrm{His}_{136}$, an axial ligand to the $\mathrm{Co}^{2+}$ of the MtaCl corrinoid co-factor that accepts $\mathrm{CH}_{3}$ from methanol and subsequently transfers it to coenzyme $M$ (Sauer et al., 1997; Randaccio et al., 2007). Neutral losses of 59-Da, sometimes observed from trimethylated residues, were not apparent in these spectra. Additional experiments are required to verify the source of this substitution; e.g., genetic drift (DNA), sloppy transcription (RNA), miscoding (translation), or posttranslational modification, but at present trimethylation is favored.

Despite the larger protein amounts available for the two M. mazei orthologs, MM1648 (MtaC1) and MM1073 


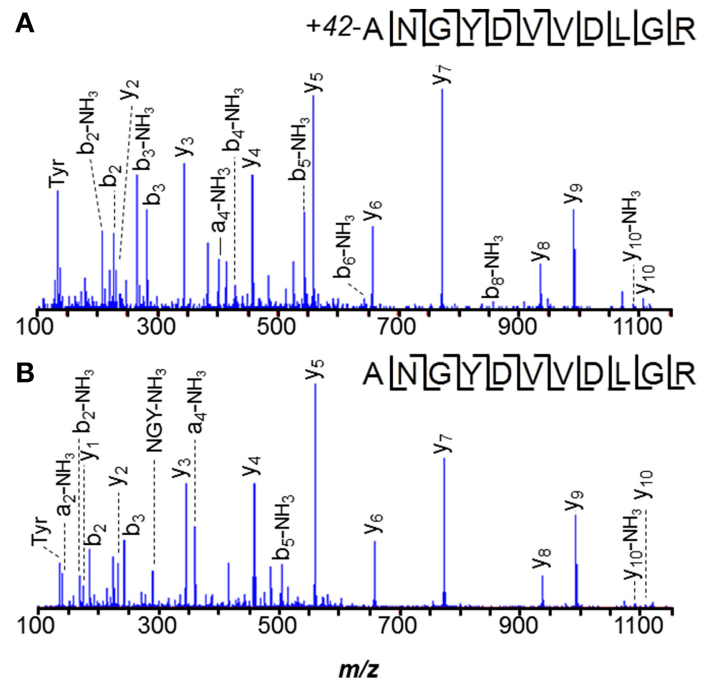

FIGURE 3 | Peptide ANGYDVVDLGR of $M$. acetivorans protein MA0456 (MtaC1) is present in two forms. (A) Peptide with $N$-terminal +42-Da modification, consistent with trimethylation or a $\mathrm{C}_{3} \mathrm{H}_{6}$ composition. (B) Unmodified peptide.

(MtaC2), 42-Da incremented peptides ANGYNVVDLGR and ANGYDVVDLGR, respectively, were not observed. Only unmodified and -17 Da variants were observed, with the latter reflecting succinimides, unremarkable for Asn-Gly bonds. Instead, a semitryptic peptide was observed in M. mazei MM1073 (MtaC2). Peptide 138-150, C*HVAEGDVHDIGK was incremented by 25$\mathrm{Da}$ at its $\mathrm{N}$-terminus, consistent with cyanylation see the MS/MS spectrum displayed in Figure 4). Such modification seems remarkable, but may reflect a radical-induced side reaction given that this region binds the corrinoid cofactor. A classic chemical cleavage scheme relies on $S$-cyanocysteine's base-catalyzed ability to cleave the $N$-terminal peptide bond to yield iminothiazolidinyl peptides (Jacobson et al., 1973; Degani and Patchornik, 1974; Nefsky and Bretscher, 1989; Wu and Watson, 1997). Uncleaved S-cyanocysteine 134-150 (GTVVCHVAEGDVHDIGK) was not observed by LC-MS. At present, we cannot differentiate in vivo modification from modification induced by exposure to air during sample handling.

Limited experiments performed on $M$. acetivorans MA0456 (MtaC1), revealed only unmodified tryptic peptide GTVVCHVAEGDVHDIGK (124-140), but those studies cannot be considered conclusive, because smaller quantities of protein and a narrower range of sample handling conditions were pursued. In particular, the $M$. acetivorans samples were reduced with dithiothreitol (DTT), whereas cyanylated M. mazei protein was observed from untreated samples. Excess DTT removes the cyanide group from internal cysteines, thereby stopping the cleavage reaction (Degani and Patchornik, 1974; Nefsky and Bretscher, 1989).

\section{PROTEIN COMPLEXES FOR ENERGY TRANSFER-ACOUISITION}

Numerous protein complexes were recovered by Con A fractionation, including, tetrahydromethanopterin $S$-methyl

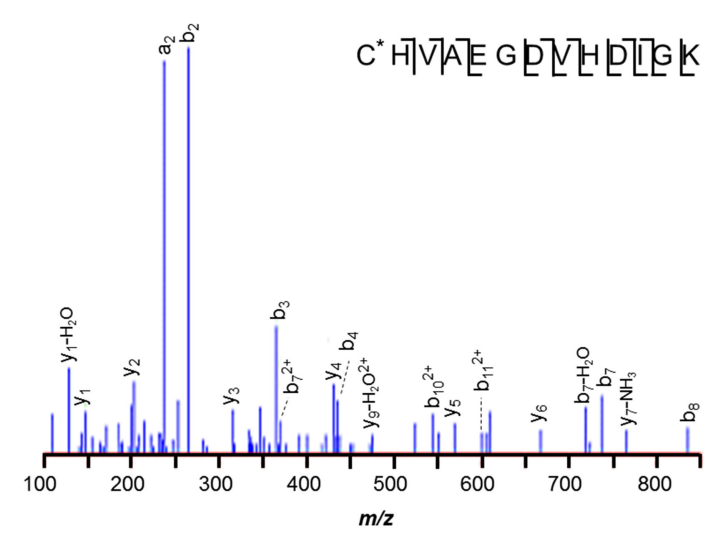

FIGURE 4 | M. mazei semi-tryptic peptide from MM1073 (MtaC2). Peptide 138-150, C*HVAEGDVHDIGK is incremented by 25-Da at its $\mathrm{N}$-terminus, consistent with cyanylation. The sequence is common to segment 138-150 of methanol corrinoid proteins MM1648 (MtaC1) and MM1073 (MtaC2).

transferase (mtr), methylcobalamin:CoM methyltransferase (mta), methyl CoM reductase $(m c r), \mathrm{F}_{420} \mathrm{H}_{2}$ dehydrogenase $(f p o)$, heterodisulfide reductase $(h d r)$, and $\mathrm{A}_{1} \mathrm{~A}_{0} \mathrm{H}^{+}$ATPase (aha). Conceivably, Con A fractionation could show utility for enriching select M. mazei protein complexes in support of other studies or for additional characterization. Hence, we considered which subunits were identified in the eluate. A second reason for interest in the proteins and complexes detected is that mass spectrometrists often discount the presence of certain proteins in mixtures as reflective of contamination. These assumptions are not always justified. Here we sought evidence that proteins not annotated as surface- or membrane-localized, or not known to be glycosylated might rationally be carried along in the Con A fractionation by interactions with other proteins. Should most of the detected proteins be rationalized, there would be additional impetus to explore the cellular localization of any remaining proteins.

All eight tetramethyl methanopterin $S$-methyltransferase subunits (MtrABCDEFGH) were detected, including integral membrane proteins MtrC, MtrD, and MtrE (Fischer et al., 1992; Lienard et al., 1996; Lienard and Gottschalk, 1998; Thauer, 1998; Kahnt et al., 2007). The abundance of this complex enabled $N$ - and $C$-termini to be defined for many of the subunits, as well as providing some unexpected observations. Tryptic peptides IVTDEDKGIFDR (40-51) and IVTDXXDK (40-46), with $X$ corresponding to Glu-28 Da, were observed from catalytic subunit MtrH (MM1540). The latter peptide could reflect decarboxylation of $\mathrm{Glu}_{44}$, perhaps from exposure to reactive species.

Strikingly, Con A binding recovered representatives from all types of the organism's membrane-bound hydrogenases involved in electron transfer: the $\mathrm{F}_{420}$ non-reducing hydrogenase (Vht), Ech hydrogenase, and the $\mathrm{F}_{420} \mathrm{H}_{2}$ dehydrogenase (Fpo) (Künkel et al., 1997, 1998). These included seven proteins encoded in the $\mathrm{F}_{420} \mathrm{H}_{2}$ dehydrogenase gene cluster MM2479-2491, the hydrogenase components EchA and EchB (MM2320, MM2321), and $\mathrm{F}_{420}$-non-reducing hydrogenase MM2171 (VhtC). Previously, we 
A

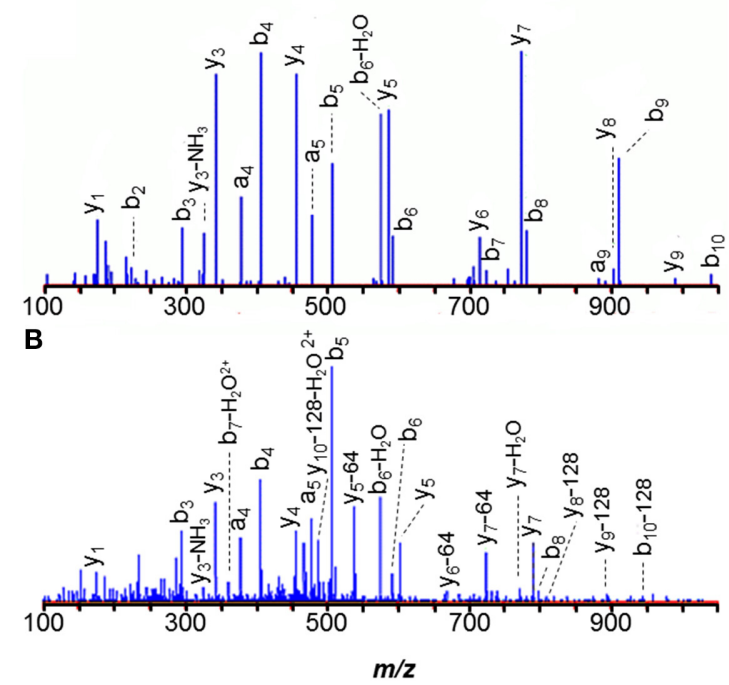

FIGURE 5 | MS/MS spectra of the 271-284 tryptic peptides from the alpha subunit of membrane-associated methyl coenzyme $M$ reductase (McrA) show that the 1- $\mathbf{N}$-methyl histidine residue signals its presence with strongly enhanced $\boldsymbol{b}$-ion intensities. (A) M. mazei MM1240

$H^{*}$ AALVSMGEMLPAR, and (B) M. acetivorans MA4546 $H^{*}$ AALVSM ${ }^{\circ}$ GEM $^{\circ \times}$ LPAR.

recovered a large subunit of the $\mathrm{F}_{420} \mathrm{H}_{2}$ dehydrogenase [MM2170 (VhtA) or MM2313] by biotin-tagging (Francoleon et al., 2009). Membrane-bound heterodisulfide reductase proteins HdrE and HdrD (MM1843 and MM1844) were also recovered, as was MM0628, provider of reduced $\mathrm{F}_{420}$ (Bäumer et al., 2000; Thauer et al., 2008).

The methyl coenzyme $\mathrm{M}$ product $\left(\mathrm{CH}_{3}-\mathrm{S}-\mathrm{CoM}\right)$ is reductively demethylated by coenzyme $\mathrm{B}(\mathrm{CoB}-\mathrm{SH})$ in a process catalyzed by the membrane-associated methyl coenzyme $M$ reductase complex, Mcr (Hoppert and Mayer, 1990). All three $\alpha, \beta$, and $\gamma$ subunits (MM1240, McrA; MM1244, McrB; MM1241, McrC) were eluted from concanavalin A. From $\alpha$-subunit McrA, $1-N$ methyl-histidine was observed in peptide HAALVSMGEMLPAR (271-284), consistent with previous observations in M. barkeri (Grabarse et al., 2000). Because peptides spanning residues 285,465 , and 472 were not recovered, we could not determine if the unusual amino acids 5-methylarginine, $S$-methylcysteine, and thioglycine were present, as in other methanogens (Grabarse et al., 2000; Kahnt et al., 2007). However, the $N$-terminus was found to be acetylated. The peptide 271-284 MS/MS spectrum, illustrated in Figure 5A, demonstrates that the 1-N-methyl histidine residue enhances $b$-ion intensities from tryptic peptides. Peptides 271-284 and 1-7 were only observed in modified form. Similarly, 1-N-methyl histidine was found in the active site region of the M. acetivorans ortholog, MA4546. (See Figure 5B).

That protein products from 8 of $10 \mathrm{~A}_{1} \mathrm{~A}_{0}$ ATPase-related genes were recovered via Con A elution, (ahaABCDE, ahaHIK) suggests that this capture method may be useful in isolating these unstable complexes (Müller et al., 1999). Previous experiments (Lemker et al., 2001, 2003) purifying ATPase subcomplexes from $\mathrm{F}_{1} \mathrm{~F}_{0}$ ATPase-negative $E$. coli cells over-expressing the
M. mazei ahaA-ahaG operon recovered subunits A, B, C, D, and F. Questions persist regarding the participation in ATPase of $M$. mazei AhaG, considered authentic based on observation of an appropriately migrating SDS-PAGE band following heterologous expression in Escherichia coli (Lemker et al., 2001), but homologs of which are absent in several archaea. In our studies, recovery of AhaG may have been reduced, because the small $(6.3-\mathrm{kDa})$ protein is expected to yield only two tryptic peptides larger than 900 $\mathrm{Da}$, one of which is very hydrophobic. Although the mass spectrometer is capable of detecting tryptic peptides below $900 \mathrm{Da}$ in mass, the peptides are often lost upstream in reversed phase HPLC, because their hydrophilicity causes them to elute with salt. Large hydrophobic peptides are also problematic for the chromatography because they fail to elute during the analysis. Thus, we cannot rule out $A$ haG as a component of the $\mathrm{A}_{1} \mathrm{~A}_{0}$ ATPase.

\section{PROTEIN COMPLEXES FOR METHANOL METABOLISM}

Observed in these studies were products from two of the three operons coding methanol-specific methyl cobalamin:CoM methyltransferases: (1) MtaA1 (MM1070) with heterodimeric MtaB2/MtaC2 (MM1074/MM1073), and (2) MtaB1/MtaC1 (MM1647/MM1648). The MtaB/MtaC complexes transfer a methyl group from methanol to the corrinoid cofactor of MtaC. Subsequently, that methyl is transferred to coenzyme M (HS-CoM), catalyzed by MtaA1. Alternative enzymes catalyzing transfer to HS-CoM (MtaA2 and MtbA), were not observed. That MtbA was absent is unsurprising, as it is specific for growth on $\mathrm{H}_{2} / \mathrm{CO}_{2}$ or trimethylamine (Harms and Thauer, 1996; Hovey et al., 2005), and Ding et al. (2002) did not identify ortholog MtaA2 from methanol-cultivated M. thermophila. However, methanol-induced expression of MtaB3 and MtaC3 was established in M. thermophila (Ding et al., 2002), leading us to address their absence in our data. First, we would not expect these methyl transferases to bind concanavalin A or associate with Con A binders, because MtaB3 and MtaC3 are generally considered soluble. Also, several MtaB3 (MM0175) peptides are non-unique, (shared with other isozymes) complicating its identification from complex mixtures. DNA microarray analyses indicated that $m t a B 1 / m t a C 1$ were induced $10-33 \mathrm{X}$ in methanol, while $m t a B 2 / m t a C 2$ were induced only in acetate (Hovey et al., 2005). Quantifying roughly, by comparing numbers of peptides recovered, we see that the trend in protein abundances follows the same direction as the transcripts: 14 peptides vs. 9 for MtaB1 vs. MtaB2 and 10 peptides vs. 6 for MtaC1 vs. MtaC2.

\section{ADDITIONAL PROTEINS RECOVERED BY CON A}

MM0633, a hypothetical protein containing a multi-heme cytochrome $c$ domain suggested as part of a membrane-bound complex, belongs to a gene cluster showing elevated expression under aceticlastic growth (Hovey et al., 2005). In these methylotrophic studies, however, MM0633 was the only cluster member observed. As it lacks transmembrane regions, we may wonder if its presence reflects interaction with some other membrane protein or glycosylation.

The oligosaccharyl transferase (MM0647) detected in the ConA pull down experiment (Table 1) is a product of one of three aglB homologs encoded in the M. mazei genome (MM646, 
MM0647, MM2210) (Magidovich and Eichler, 2009). Its detection makes MM0647 a logical candidate for the AglB oligosaccharyl transferase that links glycans to asparagines on surface layer protein MM1976 and on other $N$-linked glycoproteins. Two minor S-layer proteins similar to MM1976, MM0467, and MM1364, were identified where the latter was also shown to be glycosylated (described below). Ongoing analyses of M. mazei $\mathrm{N}$-linked glycans will reveal more about the oligosaccharides transferred.

Proteins with roles in cobalt and iron uptake were also observed: MM2069, an iron ABC transporter, MM1999 and MM2000 involved in cobalt uptake, MM0893 (CbiM), a cobalt ATP-dependent transporter, and MM0994 (CbiC). Identifications for $\mathrm{CbiC}$ and $\mathrm{CbiM}$ were based on a single recovered peptide for each, a lower standard of confidence. Numerous other transporters were also observed.

Previously detected Hsp70 analog MM2505 and the membrane-bound ATP-dependent protease LonB were also found in Con A eluate, along with two of three subunits comprising the M. mazei thermosome (Bateman et al., 2004), a eukaryotic-type chaperonin complex. Previously, surfacebiotinylation with streptavidin affinity chromatography retrieved all 3 M. mazei subunits $[\operatorname{MM} 1379(\alpha)$, MM0072 $(\beta)$, and MM1096 $(\gamma)$ ], confirming the proposal (Trent et al., 2003) that a fraction of thermosome (or rosettasome) complexes are membrane-localized. In the present $M$. mazei lectin capture, as well as for our previous $M$. acetivorans surface-tagging and capture efforts (Francoleon et al., 2009), the thermosome $\gamma$-subunit was not recovered. Archaeal thermosomes vary in whether their double ring structures are composed of identical subunits, or of two or three different sequences; e.g., the Methanopyrus kandleri complex is homomeric (Andrä et al., 1998). Indeed, M. mazei proteins most closely related to the $M$. kandleri thermosome, MK1006, are MM1379, MM1096, and MM0072, respectively.

\section{PROTEIN EXPORT AND PROCESSING}

Machinery to transport proteins across the membrane is essential to protein secretion. Recent cryo-electron microscopy studies revealed important components of this machinery in yeast, where protein transport across the endoplasmic reticulum begins with the signal peptide of the nascent chain engaging the signal recognition particle (SRP) in the cytoplasm. Co-translational translocation is initiated when the signal peptide is transferred to the protein conducting channel, overlapping 4 binding sites on the large ribosomal subunit. The archaeal analog to translocation across the ER is transport across the cell membrane. The heterotrimeric protein-conducting channel (akin to yeast $\operatorname{Sec} 61 \alpha, \beta$, and $\gamma)$ consists of integral membrane proteins: MM2147, MM1372, and MM1009, respectively, all of which we observed (Becker et al., 2009; Kampmann and Blobel, 2009), along with accessory factors MM1424 (SecF) and MM1425 (SecD). As in Eukarya and Bacteria, ribosomes contact membranes via Sec-based sites (Ring and Eichler, 2004), consistent with our observations of associated ribosomal proteins. The SecP algorithm predicts secretion of ribosomal proteins MM1760, MM2124, MM2135, and MM2157 (Bendtsen et al., 2004a, 2005), although the relationship between non-classical secretion predictions, disordered regions, and protein-protein or protein-nucleotide interactions is yet unclear. The mass spectrometry/proteomics community often cites the presence of ribosomal proteins in cell membrane preparations as evidence of poor quality, but it is important to consider that some presence in preparations enriching membraneassociated complexes is legitimate.

Of the total number of M. mazei open reading frames detected by our study, genome sequence analysis (Deppenmeier et al., 2002) annotated about $20 \%$ as hypothetical, thus highlighting the efficacy of the Con A pull-down approach for discovery. Of the 28 hypothetical proteins, 24 were predicted to be secreted by Exprot, SignalP, SecP, and/or LipoP (Juncker et al., 2003; Bendtsen et al., 2004a,b, 2005; Saleh et al., 2010). In addition, we find that hypothetical proteins MM0716 and MM1364 are glycosylated. Glycosylation of MM1364 correlates with homology to known Methanosarcinae S-layer proteins (Francoleon et al., 2009), that also bear glycans.

\section{CONCLUSIONS}

LC-MS/MS analyses of proteolytically-digested concanavalin A eluate from M. mazei Göl cell lysates led to the identification of 154 proteins. Among these, constituents of membranebound or membrane-associated complexes known from the literature were well-represented, including all 8 subunits of tetrahydromethanopterin S-methyl transferase (Mtr), seven proteins encoded by the $\mathrm{F}_{420} \mathrm{H}_{2}$ dehydrogenase fpo operon, the 3 subunits of methyl coenzyme $\mathrm{M}$ reductase (Mcr), the protein products from 8 of $10 \mathrm{~A}_{1} \mathrm{~A}_{0}$ ATPase-related genes (ahaABCDE$H I K)$, and components of the machinery translocating proteins across the cell membrane [protein channel constituents MM2147, MM1372, and MM1009 and accessory factors MM1424 (SecF) and MM1425 (SecD)]. All of these proteins do not bear Con A-interacting saccharides, because lectin binding is performed under non-denaturing conditions. However, the results can be useful in considering strategies to enrich or isolate select membrane complexes from M. mazei, and perhaps other Methanosarcinae, in order to monitor dynamic changes in protein modifications and/or retrieve complexes from strains not engineered to synthesize tagged proteins for easy retrieval.

Tandem mass spectrometry data associated with protein identifications can be mined to recover novel information that is not automatically provided by the high-throughput analyses. Here it was found that $S$-layer protein MM1976 was present in multiple forms, including four variants of its $\mathrm{N}$-terminal peptide ADVIEIR. Instances of protein formylation, methyl esterification, methylation, and cyanylation were also found. Knowledge of unanticipated modifications, even if not providing immediate insight, does suggest features to monitor for evidence of dynamic changes. Knowledge gained by data mining can also complement what is obtained from experiments specifically targeting that modification, because the experimental conditions (e.g., chromatography resin and elution conditions) are often different. A high throughput LC-MS/MS run injects only a few hundred nanograms of a peptide mixture. Further effort is underway to characterize unknown glycans, the sites they modify, and 
other post-translational modifications, particularly in extensively modified S-layer protein MM1976.

$N$-termini recovered from a subset of proteins secreted to the membrane or cell surface provide a dataset for comparison to signal peptide algorithms. Disagreement between the number of proteins predicted vs. detected with signal peptide-excised $N$ termini suggests that leaderless secretion is of greater importance than present models imply.

\section{ACKNOWLEDGMENTS}

This research was supported by the Department of Energy Biosciences Division grant award DE-FG02-08ER64689 to RPG, by the UCLA-DOE Institute of Genomics and Proteomics (DEFC03-02ER6342) to JL and RPG, by the Ruth L. Kirschstein National Research Service Award (Grant GM007185) to DL and by the National Institutes of Health (R01 GM085402) to ROL and JL.

\section{SUPPLEMENTARY MATERIAL}

The Supplementary Material for this article can be found online at: http://www.frontiersin.org/journal/10.3389/fmicb. 2015.00149/abstract

\section{REFERENCES}

Albers, S.-V., Szabó, Z., and Driessen, A. J. M. (2006). Protein secretion in the archaea: multiple paths towards a unique cell surface. Nat. Rev. Microbiol. 4, 537-547. doi: 10.1038/nrmicro1440

Andrä, S., Frey, G., Jaenicke, R., and Stetter, K. O. (1998). The thermosome from Methanopyrus kandleri possesses an $\mathrm{NH}_{4}^{+}$-dependent atpase activity. Eur. J. Biochem. 255, 93-99. doi: 10.1046/j.1432-1327.1998.2550093.x

Antelmann, H., Tjalsma, H., Voigt, B., Ohlmeier, S., Bron, S., Van Dijl, J. M., et al. (2001). A proteomic view on genome-based signal peptide predictions. Genome Res. 11, 1484-1502. doi: 10.1101/gr.182801

Armengaud, J. (2009). A perfect genome annotation is within reach with the proteomics and genomics alliance. Curr. Opin. Microbiol. 12, 292-300. doi: 10.1016/j.mib.2009.03.005

Baenziger, J. U., and Fiete, D. (1979). Structural determinants of concanavalin a specificity for oligosaccharides. J. Biol. Chem. 254, 2400-2407.

Bandeira, N., Tsur, D., Frank, A., and Pevzner, P. A. (2007). Protein identification by spectral networks analysis. Proc. Natl. Acad. Sci. U.S.A. 104, 6140-6145. doi: 10.1073/pnas.0701130104

Bateman, A., Coin, L., Durbin, R., Finn, R. D., Hollich, V., Griffiths-Jones, S., et al. (2004). The pfam protein families database. Nucleic Acids Res. 32, D138-D141. doi: 10.1093/nar/gkh121

Bäumer, S., Ide, T., Jacobi, C., Johann, A., Gottschalk, G., and Deppenmeier, U. (2000). The $\mathrm{F}_{420} \mathrm{H}_{2}$ Dehydrogenase from Methanosarcina mazei is a RedoxDriven proton pump closely related to NADH Dehydrogenases. J. Biol. Chem. 275, 17968-17973. doi: 10.1074/jbc.M000650200

Baumgartner, C., Rejtar, T., Kullolli, M., Akella, L. M., and Karger, B. L. (2008). SeMoP: a new computational strategy for the unrestricted search for modified peptides using LC-MS/MS data. J. Proteome Res. 7, 4199-4208. doi: 10.1021/ pr800277y

Becker, T., Bhushan, S., Jarasch, A., Armache, J.-P., Funes, S., Jossinet, F., et al. (2009). Structure of monomeric yeast and mammalian Sec61 complexes interacting with the translating ribosome. Science 326, 1369-1373. doi: 10.1126/science. 1178535

Bendtsen, J. D., Jensen, L. J., Blom, N., Von Heijne, G., and Brunak, S. (2004a). Feature based prediction of non-classical and leaderless protein secretion. Protein Eng. Des. Sel. 17, 349-356. doi: 10.1093/protein/gzh037

Bendtsen, J. D., Kiemer, L., Fausbøll, A., and Brunak, S. (2005). Non-classical protein secretion in bacteria. BMC Bioinformatics 5:58. doi: 10.1186/14712180-5-58

Bendtsen, J. D., Nielsen, H., Von Heijne, G., and Brunak, S. (2004b). Improved prediction of signal peptides: signalP 3.0. J. Mol. Biol. 340, 783-795. doi: 10.1016/j.jmb.2004.05.028
Blom, N., Ponten, T. S., Gupta, R., Gammeltoft, S., and Brunak, S. (2004). Prediction of post-translational glycosylation and phosphorylation of proteins from the amino acid sequence. Proteomics 4, 1633-1649. doi: 10.1002/pmic.200300771

Bose, A., Pritchett, M. A., Rother, M., and Metcalf, W. W. (2006). Differential regulation of the three methanol methyltransferase isozymes in Methanosarcina acetivorans C2A. J. Bacteriol. 188, 7274-7283. doi: 10.1128/JB.00535-06

Cooper, H. J., Håkansson, K., and Marshall, A. G. (2005). The role of electron capture dissociation in biomolecular analysis. Mass Spectrom. Rev. 24, 201-222. doi: $10.1002 /$ mas. 20014

Creasy, D. M., and Cottrell, J. C. (2004). Unimod: protein modifications for mass spectrometry. Proteomics 4, 1534-1536. doi: 10.1002/pmic.200300744

Creasy, D. M., and Cottrell, J. S. (2002). Error tolerant searching of uninterpreted tandem mass spectrometry data. Proteomics 2, 1426-1434. doi: 10.1002/16159861(200210)2:10<1426::AID-PROT1426>3.0.CO;2-5

Debray, H., Decout, D., Strecker, G., Spik, G., and Montreuil, J. (1981). Specificity of twelve lectins towards oligosaccharides and glycopeptides related to $n$-glycosylproteins. Eur. J. Biochem. 117, 41-55. doi: 10.1111/j.14321033.1981.tb06300.x

Degani, Y., and Patchornik, A. (1974). Cyanylation of sulfhydryl groups by 2-nitro-5-thiocyanobenzoic acid. High-yield modification and cleavage of peptides at cysteine residues. Biochemistry 13, 1-11. doi: 10.1021/bi006 98a001

Deppenmeier, U., Johann, A., Hartsch, T., Merkl, R., Schmitz, R. A., MartinezArias, R., et al. (2002). The genome of Methanosarcina mazei: evidence for lateral gene transfer between Bacteria and Archaea. J. Mol. Microbiol. Biotechnol. $4,453-461$.

Ding, Y.-H. R., Zhang, S.-P., Tomb, J.-F., and Ferry, J. G. (2002). Genomic and proteomic analyses reveal multiple homologs of genes encoding enzymes of the methanol:coenzyme m methyltransferase system that are differentially expressed in methanol- and acetate-grown Methanosarcina thermophila. FEMS Microbiol. Lett. 215, 127-132. doi: 10.1111/j.1574-6968.2002.tb11381.x

Dormeyer, W., Mohammed, S., Van Breukelen, B., Krijgsveld, J., and Heck, A. J. R. (2007). Targeted analysis of protein termini. J. Proteome Res. 6, 4364-4645. doi: 10.1021/pr070375k

Eichler, J. (2003). Facing extremes: archaeal surface-layer (glyco)proteins. Microbiology 149, 3347-3351. doi: 10.1099/mic.0.26591-0

Elzanowski, A., and Ostell, J. (2013). The Genetic Codes [Online]. National Center for Biotechnology Information (NCBI). Available online at: http://www. ncbi.nlm.nih.gov/Taxonomy/Utils/wprintgc.cgi?mode $=c$ (Accessed August 30 2014).

Falb, M., Aivaliotis, M., Garcia-Rizo, C., Bisle, B., Tebbe, A., Kliein, C., et al. (2006). Archaeal $N$-terminal protein maturation commonly involves $N$-terminal acetylation: a large-scale proteomics survey. J. Mol. Biol. 362, 915-924. doi: 10.1016/j.jmb.2006.07.086

Falkner, J. A., Falkner, J. W., Yocum, A. K., and Andrews, P. C. (2008). A spectral clustering approach to MS/MS identification of post-translational modifications. J. Proteome Res. 7, 4614-4622. doi: 10.1021/pr800226w

Fischer, R., Gärtner, P., Yeliseev, A., and Thauer, R. K. (1992). N $\mathrm{N}^{5}$ Methyltetrahydromethanopterin: coenzyme $M$ methyltransferase in methanogenic archaebacteria is a membrane protein. Arch. Microbiol. 158, 208-217. doi: 10.1007/BF00290817

Fournier, C. T., Cherny, J. J., Truncali, K., Robbins-Pianka, A., Lin, M. S., Krizanc, D., et al. (2012). Amino termini of many yeast proteins map to downstream start codons. J. Prot. Res. 11, 5712-5719. doi: 10.1021/pr300538f

Francoleon, D. R., Boontheung, P., Yang, Y., Kim, U., Ytterberg, A. J., Denny, P. A., et al. (2009). S-layer, surface-accessible, and concanavalin A binding proteins of Methanosarcina acetivorans and Methanosarcina mazei. J. Prot. Res. 8, 1972-1982. doi: 10.1021/pr800923e.

Gallien, S., Perrodou, E., Carapito, C., Deshayes, C., Reyrat, J. M., Van Dorsselaer, A., et al. (2009). Orthoproteogenomics: multiple proteomes investigation through orthology and a new MS-based protocol. Genome Res. 19, 128-135. doi: $10.1101 /$ gr.081901.108

Gevaert, K., Goethals, M., Martens, L., Van Damme, J., Staes, A., Thomas, G. R., et al. (2003). Exploring proteomes and analyzing protein processing by mass spectrometric identification of sorted N-terminal peptides. Nat. Biotechnol. 21, 566-569. doi: $10.1038 / \mathrm{nbt} 810$

Grabarse, W., Halhlert, F., Shima, S., Thauer, R. K., and Ermler, U. (2000). Comparison of three Methyl-Coenzyme $\mathrm{M}$ reductases from phylogenetically 
distant organisms: unusual amino acid modification, conservation and adaptation. J. Mol. Biol. 303, 329-344. doi: 10.1006/jmbi.2000.4136

Hahne, H., Pachi, F., Ruprecht, B., Maier, S. K., Klaeger, S., Helm, D., et al. (2013). DMSO enhances electrospray response, boosting sensitivity of proteomic experiments. Nat. Methods 10, 989-991. doi: 10.1038/nmeth.2610

Harms, U., and Thauer, R. K. (1996). Methylcobalamin:coenzyme M methyltransferase isoenzymes MtaA and MtbA from Methanosarcina barkeri. Eur. J. Biochem. 235, 653-659. doi: 10.1111/j.1432-1033.1996.00653.x

Hippler, B., and Thauer, R. K. (1999). The energy conserving methyltetrahydromethanopterin:coenzyme $\mathrm{M}$ methyltransferase complex from methanogenic archaea: function of the subunit MtrH. FEBS Lett. 449, 165-168. doi: 10.1016/S0014-5793(99)00429-9

Hoelz, D. J., Arnold, R. J., Dobrolecki, L. E., Abdel-Aziz, W., Loehrer, A. P., Novotny, M. V., et al. (2006). The discovery of labile methyl esters on proliferating cell nuclear antigen by MS/MS. Proteomics 6, 4808-14818. doi: 10.1002/pmic.200600142

Hoppert, M., and Mayer, F. (1990). Electron microscopy of native and artificial methylreductase high-molecular-weight complexes in strain Gö1 and Methanococcus voltae. FEBS Lett. 267, 33-37. doi: 10.1016/0014-5793(90) 80281-M

Hovey, R., Lentes, S., Ehrenreich, A., Salmon, K., Saba, K., Gottschalk, G., et al. (2005). DNA microarray analysis of Methanosarcina mazei Göl reveals adaptation to different methanogenic substrates. Mol. Gen. Genomics 273, 225-239. doi: 10.1007/s00438-005-1126-9

Howe, C. J., Auffret, A. D., Doherty, A., Bowman, C. M., Dyer, T. A., and Gray, J. C. (1982). Location and nucleotide sequence of the gene for the proton translocating subunit of wheat chloroplast ATP synthase. Proc Natl Acad Sci U.S.A. 79, 6903-6907.

Jacobson, G. R., Schaffer, M. H., Stark, G. R., and Vanaman, T. C. (1973). Specific chemical cleavage in high yield at the amino peptide bonds of cysteine and cystine residues. J. Biol. Chem. 248, 6583-6591.

Jaipuri, F. A., Collet, B. Y. M., and Pohl, N. L. (2008). Synthesis and quantitative evaluation of glycero- $D$-manno-heptose binding to concanavalin A by fluorous-tag assistance. Angew. Chem. Int. Ed. 47, 1707-1710. doi: 10.1002/anie. 200704262

Juncker, A. S., Willenbrock, H., Von Heijne, G., Brunak, S., Nielsen, H., and Krogh, A. (2003). Prediction of lipoprotein signal peptides in gram-negative bacteria. Protein Sci. 12, 1652-1662. doi: 10.1110/ps.0303703

Kahnt, J., Buchenau, B., Mahlert, F., Krüger, M., Shima, S., and Thauer, R. K. (2007). Post-translational modifications in the active site region of MethylCoenzyme $\mathrm{M}$ reductase from methanogenic and methanotrophic archaea. FEBS J. 274, 4913-4921. doi: 10.1111/j.1742-4658.2007.06016.x

Kampmann, M., and Blobel, G. (2009). Nascent proteins caught in the act. Science 326, 1352-1353. doi: 10.1126/science.1183690

Kim, J.-S., Dai, Z., Aryal, U. K., Moore, R. J., Camp, I. D. G., and Qian, W.-J. (2013). Resin-assisted enrichment of n.terminal peptides for characterizing proteolytic processing. Anal. Chem. 85, 6826-6832. doi: 10.1021/ac401000q

Klunker, D., Haas, B., Hirtreiter, A., Figueiredo, L., Naylor, D. J., Pfeifer, G., et al. (2003). Coexistence of group I and group II chaperonins in the archaeon Methanosarcina mazei. J. Biol. Chem. 278, 33256-33267. doi: 10.1074/jbc.M302018200

Kornfeld, R., and Ferris, C. (1975). Interaction of immunoglobulin glycopeptides with concanavalin A. J. Biol. Chem. 250, 2614-2619.

Kozak, M. (1997). Interpreting cDNA sequences: some insights from studies on translation. Mamm. Genome 7, 563-574.

Krätzer, C., Carini, P., Hovey, R., and Deppenmeier, U. (2009). Transcriptional profiling of methyltransferase genes during growth of Methanosarcina mazei on Trimethylamine. J. Bacteriol. 191, 5108-5115. doi: 10.1128/JB.00420-09

Künkel, A., Vaupel, M., Heim, S., Thauer, R. K., and Hedderich, R. (1997). Heterodisulfide reductase from methanol-grown cells of Methanosarcina barkeri is not a flavoenzyme. Eur. J. Biochem. 244, 226-234. doi: 10.1111/j.14321033.1997.00226.x

Künkel, A., Vorholt, J. A., Thauer, R. K., and Hedderich, R. (1998). An Escherichia coli Hydrogenase-3-type hydrogenase in methanogenic archaea. FEBS J. 252, 467-476. doi: 10.1046/j.1432-1327.1998.2520467.x

Lemker, T., Grüber, G., Schmid, R., and Müller, V. (2003). Defined subcomplexes of the A1 ATPase from the Archaeon Methanosarcina mazei Gö1: biochemical properties and redox regulation. FEBS Letters 544, 206-209. doi: 10.1016/S00145793(03)00496-4
Lemker, T., Ruppert, C., Stöger, H., Wimmers, S., and Müller, V. (2001). Overproduction of a functional A1 ATPase from the Archaeon Methanosarcina Gö1 in Escherichia coli. Eur. J. Biochem. 268, 3744-3750. doi: 10.1046/j.14321327.2001.02284.x

Lienard, T., Becher, B., Marschall, M., Bowien, S., and Gottschalk, G. (1996). Sodium ion translocation by $\mathrm{N}^{5}$-methyltetrahydromethanopterin : coenzyme M methyltransferase from Methanosarcina mazei Göl reconstituted in ether lipid liposomes. Eur. J. Biochem. 239, 857-864. doi: 10.1111/j.14321033.1996.0857u.x

Lienard, T., and Gottschalk, G. (1998). Cloning, sequencing and expression of the genes encoding the sodium translocating $\mathrm{N}^{5}$ Methyltetrahydromethanopterin:coenzyme M methyltransferase of the methyloptrophic archaeon Methanosarcina mazei Gö1. FEBS Lett. 425, 204-208. doi: 10.1016/S0014-5793(98)00229-4

Magidovich, H., and Eichler, J. (2009). Glycosyltransferases and oligosaccharyltransferases in archaea: putative components of the N-Glycosylation pathway in the third domain of life. FEMS Microbiol. Lett. 300, 122-130. doi: 10.1111/j.1574-6968.2009.01775.x

Mechref, Y. (2012). Use of CID/ETD mass spectrometry to analyze glycopeptides. Curr. Protoc. Protein Sci. 68:12.11.1-12.1.11. doi: 10.1002/0471140864. ps1211s68

Meinnel, T., and Giglione, C. (2008). Tools for analyzing and predicting $N$-Terminal protein modifications. Proteomics 8, 626-649. doi: 10.1002/pmic. 200700592

Menschaert, G., Vandekerckhove, T. T. M., Landuyt, B., Hayakawa, E., Schoofs, L., Luyten, W., et al. (2009). Spectral clustering in peptidomics studies helps to unravel modification profile of biologically active peptides and enhances peptide identification rate. Proteomics 9, 4381-4388. doi: 10.1002/pmic.200900248

Messner, P. (2009). Prokaryotic protein glycosylation is rapidly expanding from "curiosity" to "ubiquity". Chem. Biochem. 10, 2151-2154. doi: 10.1002/cbic. 200900388

Müller, V., Ruppert, C., and Lemker, T. (1999). Structure and Function of the $\mathrm{A}_{1} \mathrm{~A}_{0}$ ATPases from methanogenic archaea. J. Bioenerg. Biomembr. 31, 15-27.

Nefsky, B., and Bretscher, A. (1989). Landmark mapping: a general method for localizing cysteine residues within a protein. Proc Nat. Acad. Sci. U.S.A. 86, 3549-3553.

Ogorzalek Loo, R. R., Du, P., Loo, J. A., and Holler, T. (2002). In-vivo labeling: a glimpse of the dynamic proteome and additional constraints for protein identification. J. Am. Soc. Mass Spectrom. 13, 804-812. doi: 10.1016/S10440305(02)00408-7

Parker, K. C., Garrels, J. I., Hines, W., Butler, E. M., Mckee, A. H. Z., Patterson, D., et al. (1998). Identification of yeast proteins from two-dimensional gels. working out spot cross-contamination. Electrophoresis 19, 1920-1932. doi: 10.1002/elps.1150191110

Patrie, S. M., Ferguson, J. T., Robinson, D. E., Whipple, D., Rother, M., Metcalf, W. W., et al. (2006). Top-Down Mass Spectrometry of $<60 \mathrm{kDa}$ proteins from Methanosarcina acetivorans using Q-FTMS with automated octopole collisionally activated dissociation (OCAD). Mol. Cell. Proteomics 5, 14-36. doi: 10.1074/mcp.M500219-MCP200

Prats, A. C., Vagner, S., Prats, H., and Amalric, F. (1992). Cis-Acting elements involved in the alternative translation initiation process of human basic fibroblast growth factor mRNA. Mol. Cell. Biol. 12, 4796-4805.

Randaccio, L., Geremia, S., and Wuerges, J. (2007). Crystallography of vitamin B12 proteins. J. Organometallic Chem. 692, 1198-1215. doi: 10.1016/j.jorganchem.2006.11.040

Ring, G., and Eichler, J. (2004). Membrane binding of ribosomes occurs at SecYEbased sites in the archaea Haloferax volcanii. J. Mol. Biol. 336, 997-1010. doi: 10.1016/j.jmb.2004.01.008

Rohlin, L., Leon, D. R., Kim, U., Loo, J. A., Ogorzalek Loo, R. R., and Gunsalus, R. P. (2012). Identification of the major expressed S-Layer and cell surfacelayer-related proteins in the model methanogenic archaea: Methanosarcina barkeri fusaro and Methanosarcina acetivorans C2A. Archaea 2012:873589. doi: 10.1155/2012/873589

Running, W., and Reilly, J. P. (2009). Ribosomal proteins of Deinococcus radiodurans: their solvent accessibility and reactivity. J. Proteome Res. 8, 1228-1246. doi: $10.1021 /$ pr800544y

Russo, A., Chandramouli, N., Zhang, L., and Deng, H. (2008). Reductive glutaraldehydation of amine groups for identification of protein N-termini. J. Proteome Res. 7, 4178-4182. doi: 10.1021/pr800224v 
Saleh, M., Song, C., Nasserulla, S., and Leduc, L. G. (2010). Indicators from archaeal secretomes. Microbiol. Res. 165, 1-10. doi: 10.1016/j.micres.2008.03.002

Sauer, K., Harms, U., and Thauer, R. K. (1997). Methanol:coenzyme M methyltransferase from Methanosarcina barkeri. purification, properties, and encoding genes of the corrinoid protein MT1. Eur. J. Biochem. 243, 670-677. doi: 10.1111/j.1432-1033.1997.t01-1-00670.x

Savitski, M. M., Nielsen, M. L., and Zubarev, R. A. (2005). New data baseindependent, sequence tag-nased scoring of peptide MS/MS data validates mowse scores, recovers below threshold data, singles out modified peptides, and assesses the quality of MS/MS techniques. Mol. Cell. Proteomics 4, 1180-1188. doi: 10.1074/mcp.T500009-MCP200

Savitski, M. M., Nielsen, M. L., and Zubarev, R. A. (2006). Modificomb, a new proteomic tool for mapping substoichiometric post-translational modifications, finding novel types of modifications, and fingerprinting complex protein mixtures. Mol. Cell. Proteomics 5, 935-948. doi: 10.1074/mcp.T500034MCP200

Schmidt, A., Kellermann, J., and Lottspeich, F. (2005). A novel strategy for quantitative proteomics using isotope-coded protein labels. Proteomics 5, 4-15. doi: 10.1002/pmic. 200400873

Sebald, W., Graf, T., and Lukins, H. B. (1979). The Dicyclohexylcarbodiimidebinding protein of the mitochondrial ATPase complex from Neurospora crassa and Saccharomyces cerevisiae identification and isolation. Eur. J. Biochem. 93, 587-599. doi: 10.1111/j.1432-1033.1979.tb12859.x

Shen, P.-T., Hsu, J.-L., and Chen, S.-H. (2007). Dimethyl isotope-coded affinity selection for the analysis of free and blocked $N$-Termini of proteins using LCMS/MS. Anal. Chem. 79, 9520-9530. doi: 10.1021/ac701678h

Silva, J. C., Denny, R., Dorschel, C. A., Gorenstein, M., Kass, I. J., Li, G. Z., et al. (2005). Quantitative proteomic analysis by accurate mass retention time pairs. Anal. Chem. 77, 2187-2200. doi: 10.1021/ac048455k

Sowers, K. R., Boone, J. E., and Gunsalus, R. P. (1993). Disaggregation of Methanosarcina spp. and growth as single cells at elevated osmolarity. Appl. Environ. Microbiol. 59, 3832-3839.

Thauer, R. K. (1998). Biochemistry of methanogenesis: a tribute to marjory stephenson. Microbiology 144, 2377-2406. doi: 10.1099/00221287-1449-2377

Thauer, R. K., Kaster, A.-K., Seedorf, H., Buckel, W., and Hedderich, R. (2008). Methanogenic archaea: ecologically relevant differences in energy conservation. Nat. Rev. Microbiol. 6, 579-591. doi: 10.1038/nrmicro1931

Trent, J. D., Kagawa, H. K., Paavola, C. D., Mcmillan, R. A., Howard, J., Jahnke, L., et al. (2003). Intracellular localization of a group II chaperonin indicates a membrane-related function. Proc. Natl. Acad. Sci. U.S.A. 100, 15589-15594. doi: 10.1073/pnas.2136795100

Venne, A. S., Vögtle, F.-N., Meisinger, C., Sickmann, A., and Zahedi, R. P. (2013). Novel highly sensitive, specific, and straightforward strategy for comprehensive N.terminal proteomics reveals unknown substrates of the mitochondrial peptidase Icp55. J. Prot. Res. 12, 3823-3830. doi: 10.1021/ pr400435d

Wilhelm, T., and Jones, A. M. E. (2014). Identification of related peptides through the analysis of fragment ion mass shifts. J. Prot. Res. 13, 4002-4011. doi: $10.1021 /$ pr500347e
Wu, J., and Watson, J. T. (1997). A novel methodology for assignment of disulfide bond pairings in proteins. Protein Sci. 6, 391-398. doi: 10.1002/pro.55600 60215

Xing, G., Zhang, J., Chen, Y., and Zhao, Y. (2008). Identification of four novel types of in vitro protein modifications. J. Proteome Res. 7, 4603-4608. doi: $10.1021 / \mathrm{pr} 800456 \mathrm{q}$

Xu, G., and Jaffrey, S. R. (2010). N-CLAP: global profiling of N-Termini by chemoselective labeling of the $\alpha$-amine of proteins. Cold Spring Harb. Protoc. 10: pdb.prot5528. doi: 10.1101/pdb.prot5528

Yalcin, T., Khouw, C., Csizmadia, I. G., Peterson, M. R., and Harrison, A. G. (1995). Why are $b$ Ions stable species in peptide spectra? J. Am. Soc. Mass Spectrom. 6, 1165-1174. doi: 10.1016/1044-0305(95)00569-2

Yamaguchi, M., Nakayama, D., Shima, K., Kuyama, H., Ando, E., Okamura, T.A., et al. (2008). Selective isolation of N-terminal peptides from proteins and their de novo sequencing by matrix-assisted laser desorption/ionization timeof-flight mass spectrometry without regard to unblocking of N-terminal amino acids. Rapid Commun. Mass Spectrom. 22, 3313-3319. doi: 10.1002/rcm.3735

Yamazaki, S., Yamazaki, J., Nishijima, K., Otsuka, R., Mise, M., Ishikawa, H., et al. (2006). Proteome analysis of an aerobic hyperthermophilic crenarchaeon, Aeropyrum pernix K1. Mol. Cell. Prot. 5, 811-823. doi: 10.1074/mcp.M500312MCP200

Ytterberg, A. J., Peltier, J. B., and van Wijk, K. J. (2006). Protein profiling of plastoglobules in chloroplasts and chromoplasts. A surprising site for differential accumulation of metabolic enzymes. Plant Physiol. 140, 984-997. doi: 10.1104/pp.105.076083

Yurist-Doutsch, S., Chaban, B., Vandyke, D. J., Jarrell, K. F., and Eichler, J. (2008). Sweet to the extreme: protein glycosylation in archaea. Mol. Microbiol. 68, 1079-1084. doi: 10.1111/j.1365-2958.2008.06224.x

Zubarev, R. A. (2004). Electron-capture dissociation tandem mass spectrometry. Curr. Opin. Biotechnol. 15, 12-16. doi: 10.1016/j.copbio.2003.12.002

Conflict of Interest Statement: The authors declare that the research was conducted in the absence of any commercial or financial relationships that could be construed as a potential conflict of interest.

Received: 01 November 2014; accepted: 09 February 2015; published online: 05 March 2015.

Citation: Leon DR, Ytterberg AJ, Boontheung P, Kim U, Loo JA, Gunsalus RP and Ogorzalek Loo RR (2015) Mining proteomic data to expose protein modifications in Methanosarcina mazei strain Gö1. Front. Microbiol. 6:149. doi: 10.3389/fmicb. 2015.00149

This article was submitted to Microbial Physiology and Metabolism, a section of the journal Frontiers in Microbiology.

Copyright (c) 2015 Leon, Ytterberg, Boontheung, Kim, Loo, Gunsalus and Ogorzalek Loo. This is an open-access article distributed under the terms of the Creative Commons Attribution License (CC BY). The use, distribution or reproduction in other forums is permitted, provided the original author(s) or licensor are credited and that the original publication in this journal is cited, in accordance with accepted academic practice. No use, distribution or reproduction is permitted which does not comply with these terms. 